\title{
Solvent and Anion Effects on the Electrochemistry of Manganese Dipyrrin-bisphenols
}

Yuanyuan Fanga,b, W. Ryan Osterloh ${ }^{\mathrm{b}}$, Nicolas Desbois ${ }^{\mathrm{c}}$, Sandrine Pacquelet ${ }^{\mathrm{c}}$, Paul Fleurat-Lessard ${ }^{\mathrm{c}}$, Claude P. Gros ${ }^{\mathrm{c}^{*}}$ and Karl M. Kadish ${ }^{\mathrm{b}}$

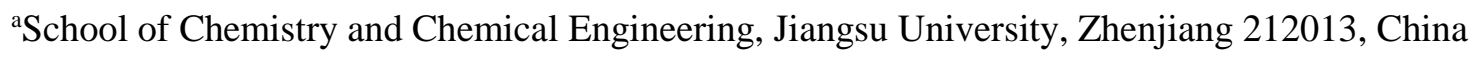

${ }^{b}$ Department of Chemistry, University of Houston, Houston, TX 77204-5003 USA

'ICMUB, UMR CNRS 6302, Université Bourgogne Franche-Comté, 21000 Dijon, France

\begin{abstract}
A series of " $\mathrm{N}_{2} \mathrm{O}_{2}$-type" manganese dipyrrin-bisphenols (DPP), formulated as (Ar)DPPMn, where $\mathrm{Ar}=$ pentafluorophenyl $\left(\mathrm{F}_{5} \mathrm{Ph}\right)$, phenyl $(\mathrm{Ph})$ or mesityl (Mes), were electrochemically and spectroscopically characterized in nonaqueous media with and without added anions in the form of tetrabutylammonium salts (TBAX where $\mathrm{X}=\mathrm{ClO}_{4}^{-}, \mathrm{PF}_{6}^{-}, \mathrm{BF}_{4}^{-}, \mathrm{F}^{-}, \mathrm{Cl}^{-}, \mathrm{OH}^{-}$or $\mathrm{CN}^{-}$). Two major one-electron reductions are observed under most solution condition, the first of which is assigned as a $\mathrm{Mn}^{\mathrm{III} / \mathrm{II}}$ process and the second as electron addition to the $\pi$-ring system as confirmed by spectroelectrochemistry. Each $\mathrm{Mn}^{\mathrm{III}}$ complex also exhibits one or two one-electron oxidations, the exact number depending upon the positive potential limit of the electrochemical solvent. The two oxidations are separated by 580-590 $\mathrm{mV}$ in $\mathrm{CH}_{3} \mathrm{CN}, 0.1 \mathrm{M} \mathrm{TBAPF}$ and are assigned as $\pi$-ring centered electron transfers to stepwise form a (Ar)DPPMn ${ }^{\mathrm{III}} \pi$-cation radical and dication under these solution conditions. Comparisons are made between redox properties of (Ar)DPPMn and manganese(III) porphyrins, corroles and corrolazines each of which contains an innocent trianionic complexing ligand. The redox behavior and spectroscopic properties of [(Ar)DPPMn ${ }^{\mathrm{n}}$ where $\mathrm{n}=0,-1$ or +1 are also compared to that of other structurally related [(Ar)DPPM $]^{\mathrm{n}}$ complexes under similar solution conditions where $\mathrm{M}=\mathrm{Co}^{\mathrm{II}}, \mathrm{Cu}^{\mathrm{II}}, \mathrm{B}^{\mathrm{III}}$ or $\mathrm{Au}^{\mathrm{III}}$.
\end{abstract}




\section{INTRODUCTION}

Numerous studies involving transition metal or main group dipyrrin bisphenols (DPP) complexes have elucidated their physicochemical properties and provided examples for possible applications of these compounds in the areas of fluorescence, ${ }^{1-9}$ catalysis, ${ }^{10-14}$ molecular recognition ${ }^{5}$ and anion binding. ${ }^{15}$

Our own laboratories have long been interested in tuning and predicting how the redox properties and oxidation states of porphyrins, ${ }^{16,17}$ corroles $^{18,19}$ and related macrocycles can be systematically varied in nonaqueous media by the judicious addition of pre-selected complexing ligands to solution, by systematic changes in the macrocycle $\beta$ - or meso-substituents and/or by changing the electrochemical solvent/supporting electrolyte system. In this regard, we recently examined a series of cobalt dipyrrin bisphenols under a variety of solution conditions ${ }^{20}$ and suggested an emerging analogy between the electrochemistry of these compounds, represented as (Ar)DPPCo, and cobalt triarylcorroles $(\mathrm{Ar})_{3} \mathrm{CorCo}$ which may or may not possess a noninnocent macrocyclic ligand depending upon the type of axial coordination. ${ }^{21}$ The current manuscript is a continuation of our studies on transition metal dipyrrin bisphenols and concentrates on elucidating the redox behavior of structurally related DPP macrocycles containing a formal $\mathrm{Mn}^{\mathrm{III}}$ central metal ion.

It is well-known that the trianionic $\mathrm{DPP}^{3-}$ macrocycle can strongly complex metal ions and exist as an innocent or noninnocent assembly, forming either a neutral dipyrrin complex with a trivalent metal ion, $\mathrm{DPP}^{3-} \mathrm{M}^{\mathrm{III}},{ }^{22}$ or a ligand-centered radical coordinated to a divalent metal ion, $\mathrm{DPP}^{\bullet 2-} \mathrm{M}^{\mathrm{II}} .{ }^{11,13,20,23,24}$ The electronic configuration of the metallodipyrrin complex formed, i.e. innocent or noninnocent, should depend on the DPP-macrocyclic substituents, the specific central metal ion and the solution conditions.

Although four-, five- and six-coordinate cobalt dipyrrin systems are analogous to four-, five- and sixcoordinate cobalt corroles (Cor), exhibiting similar electrochemical properties as well as possessing a divalent, or trivalent, metal ion and a noninnocent, or innocent, macrocyclic ligand, ${ }^{20}$ a detailed comparison between the electrochemical behavior and electronic configuration of other transition metal corroles and dipyrrins under different solution conditions has never been described in the literature. This is addressed in 
the present study which characterizes a series of $\mathrm{Mn}^{\mathrm{III}}$ dipyrrins and relates their properties to $\mathrm{Mn}^{\mathrm{III}}$ corroles and other structurally similar $\mathrm{Mn}^{\mathrm{III}}$ macrocycles under the same solution conditions.

The manganese corroles have been well-characterized in nonaqueous media and described as either innocent or noninnocent systems depending on the number and/or type of axial ligands. ${ }^{18,25-27}$ The fourcoordinate CorMn ${ }^{\mathrm{III}}$ and five coordinate sigma-bonded $\operatorname{CorMn}^{\mathrm{IV}}(\mathrm{Ph})$ complexes are innocent, while CorMnCl is noninnocent (i.e. described as $\mathrm{Cor}{ }^{\bullet} \mathrm{Mn}{ }^{\mathrm{III}} \mathrm{Cl}$ ) rather than $\mathrm{CorMn}^{\mathrm{IV}} \mathrm{Cl}^{21}{ }^{25}$ In contrast the manganese(III) dipyrrins have been characterized only as innocent assemblies, i.e. compounds possessing a $\mathrm{Mn}^{\mathrm{III}}$ center and a trianionic macrocycle, ${ }^{10,12,28}$ but little is known about how the electrochemistry of these compounds might change under different solution conditions and with different axial coordination.

Until now, there have been only two published studies focusing on the electrochemistry of DPPMn derivatives. Aukauloo, Andrioletti and coworkers ${ }^{10}$ reported the structure and electrochemistry of manganese pentafluophenyl dipyrrin-bisphenol $\left(\left(\mathrm{F}_{5} \mathrm{Ph}\right) \mathrm{DPPMn}\right)$ and also assigned the oxidation state of the manganese central metal ion as $\mathrm{Mn}^{\mathrm{III}}$. An X-ray crystal structure of the compound in the solid state revealed a pseudo di- $\mu$-oxo dimer with alkoxy bridging motifs ${ }^{10}$ where the oxygen atoms of the phenolato groups on the DPP ligand bridged the two monomeric units. However, in $\mathrm{CH}_{3} \mathrm{CN}$ containing $0.2 \mathrm{M}$ TBAPF 6 , only monomers seemed to be present as evidenced by the well-defined electrochemistry under these solution condition. Three one-electron redox processes were observed, one reduction and two oxidations, the latter of which are described by eqs 1 and 2. The electronic features associated with the first oxidation (eq 1) were also described as being consistent with a ligand-centered electron abstraction.

$$
\begin{aligned}
& (\mathrm{Ar}) \mathrm{DPPMn}^{\mathrm{III}} \rightleftharpoons\left[(\mathrm{Ar}) \mathrm{DPP}^{\bullet} \mathrm{Mn}^{\mathrm{III}}\right]^{+}+\mathrm{e}^{-} \\
& {\left[(\mathrm{Ar}) \mathrm{DPP} \mathrm{Mn}^{\mathrm{III}}\right]^{+} \rightleftharpoons[(\mathrm{Ar}) \mathrm{DPPMn}]^{2+}+\mathrm{e}^{-}}
\end{aligned}
$$

Thomas and coworkers ${ }^{12}$ also examined the electrochemical oxidation of a manganese DPP derivative in $\mathrm{CH}_{2} \mathrm{Cl}_{2}$ containing $0.1 \mathrm{M} \mathrm{TBAClO}_{4}$. The examined compound contained tert-butyl groups on the phenolic moieties, a bulky triaryl group at the meso position of the macrocycle and a methanol axial ligand. This $\mathrm{Mn}^{\mathrm{III}}$ DPP derivative exhibited two reversible ligand centered oxidations leading to the 
stepwise formation of a DPP cation radical (eq 1) and dication (eq 2). Notably, dimerization was not observed in the solid state due to the axial ligand and molecular design of the DPP ligand. ${ }^{12}$

Despite these detailed reports on the electrooxidation of the DPPMn compounds in $\mathrm{CH}_{2} \mathrm{Cl}_{2}$ and $\mathrm{CH}_{3} \mathrm{CN}$, a comprehensive electrochemical characterization of the reductions has never been carried out, and the effect of solvent or anion axial ligation on the electrochemical properties of a DPPMn synthon has yet to be reported in the literature.

This is now addressed in the current manuscript where the electrochemical and spectroscopic properties of three manganese dipyrrin bisphenol compounds, formulated as $(\mathrm{Ar}) \mathrm{DPPMn}$ where $\mathrm{Ar}=\mathrm{F}_{5} \mathrm{Ph}$, $\mathrm{Ph}$, Mes (Chart 1a), are examined in six nonaqueous solvents (dichloromethane $\left(\mathrm{CH}_{2} \mathrm{Cl}_{2}\right)$, dichloroethane $\left(\mathrm{C}_{2} \mathrm{H}_{4} \mathrm{Cl}_{2}\right)$, dimethylsulfoxide (DMSO), pyridine (Py), acetonitrile $\left(\mathrm{CH}_{3} \mathrm{CN}\right)$ and methanol $\left.\left(\mathrm{CH}_{3} \mathrm{OH}\right)\right)$ and the data compared to related manganese porphyrins, corroles and corrolazines whose structures are shown in Chart 1b. The effect of anions on the spectroscopic and electrochemical properties of (Ar)DPPM in its neutral, singly reduced and singly oxidized forms is also reported in $\mathrm{CH}_{2} \mathrm{Cl}_{2}$ containing tetrabutylammonium salts ( $\mathrm{TBAX}$ where $\mathrm{X}=\mathrm{ClO}_{4}^{-}, \mathrm{PF}_{6}^{-}, \mathrm{BF}_{4}^{-}, \mathrm{F}^{-}, \mathrm{Cl}^{-}, \mathrm{OH}^{-}$or $\mathrm{CN}^{-}$) and this data is then compared under the same solution conditions to that for reduction and oxidation of related porphyrin, ${ }^{29,30}$ corrole $^{31}$ and corrolazine ${ }^{32}$ manganese complexes, represented as $\left((\mathrm{Ar})_{4} \mathrm{PorMn}^{\mathrm{III}} \mathrm{Cl}\right),\left((\mathrm{Ar})_{3} \mathrm{CorMn}{ }^{\mathrm{III}}\right)$ and $\left(\mathrm{CzMn}^{\mathrm{III}}\right)$ respectively.

As will be shown, an easily accessible $\mathrm{Mn}^{\mathrm{III} / \mathrm{II}}$ reduction process occurs for the air-stable (Ar)DPPMn complexes, this process being significantly more facile as compared to the earlier characterized $\mathrm{Mn}^{\mathrm{III}}$ reductions of corrole or corrolazine complexes which also contain a trianionic macrocyclic ligand. 
Chart 1. Structures of (a) investigated dipyrrin bisphenols (Ar)DPPMn ${ }^{\mathrm{III}}$ and (b) related manganese porphyrin, corrole and corrolazine, formulated as $(\mathrm{Ar})_{4} \mathrm{PorMn}^{\mathrm{III}} \mathrm{Cl},(\mathrm{Ar})_{3} \mathrm{CorMn}^{\mathrm{III}}$ and $\mathrm{CzMn}{ }^{\mathrm{III}}$, respectively.

(a)
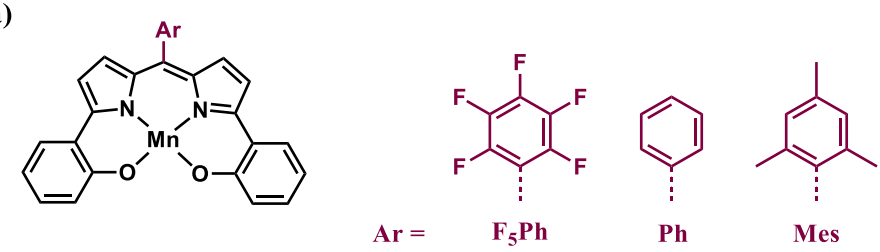

(Ar)DPPMn ${ }^{\text {III }}$

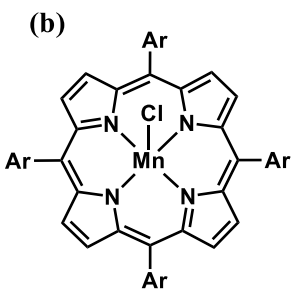

$(\mathrm{Ar})_{4} \operatorname{PorMn}^{\mathrm{III}} \mathrm{Cl}$

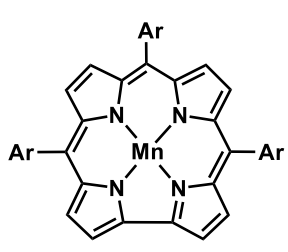

$(\mathrm{Ar})_{3} \operatorname{CorMn}^{\mathrm{III}}$

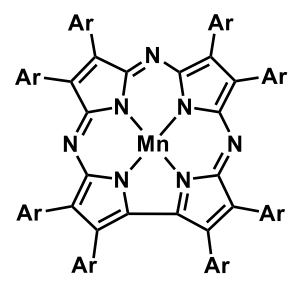

(Ar) ${ }_{8} \mathrm{CzMn}$ III

\section{RESULTS AND DISCUSSION}

Electrochemistry. The three (Ar)DPPMn complexes in Chart 1a were electrochemically investigated under a variety of solution conditions. Examples of cyclic voltammograms obtained in $\mathrm{CH}_{3} \mathrm{CN}$ containing 0.1 $\mathrm{M} \mathrm{TBAPF}_{6}$ are shown in Figure 1 and the data summarized in Table 1, where each complex is characterized by two reversible one-electron oxidations and two reversible one-electron reductions within the solvent potential limit of +1.50 to $-2.10 \mathrm{~V}$ vs SCE. The first reduction of (Ar)DPPMn is located at $E_{1 / 2}$ $=-0.56$ to $-0.67 \mathrm{~V}$ and the second at $E_{1 / 2}=-1.57$ to $-1.79 \mathrm{~V}$, with the absolute potential difference between the two processes ranging from 1.01 to $1.12 \mathrm{~V}$ as indicated in Figure 1. Each DPPMn complex also undergoes two one-electron oxidations located at $E_{1 / 2}=0.61$ to $0.71 \mathrm{~V}$ and $E_{1 / 2}=1.30$ to $1.20 \mathrm{~V}$. The separation between the two reversible oxidations ranges from 0.58 to $0.59 \mathrm{~V}$ and is essentially the same as what was reported earlier for $\left(\mathrm{F}_{5} \mathrm{Ph}\right) \mathrm{DPPMn}$ in $\mathrm{CH}_{3} \mathrm{CN} / 0.2 \mathrm{M} \mathrm{TBAPF}_{6}$, where the two electron transfers were assigned to the DPP ligand, giving the $\pi$-cation radical and dication as described by eqs 1 and $2 .{ }^{10}$

Electrochemical free energy relationships were also examined for the four reversible redox processes of the $\mathrm{Mn}^{\mathrm{III}}$ complexes in $\mathrm{CH}_{3} \mathrm{CN}$ containing $0.1 \mathrm{M} \mathrm{TBAPF}_{6}$. This correlation, given in Figure $\mathrm{S} 1$, is defined as $E_{1 / 2}=\sigma \rho,{ }^{33}$ where $E_{1 / 2}$ is the measured half-wave potential, $\sigma$ is the sum of the Hammett constants for substituents on the meso-phenyl ring (see Table 1) and $\rho$ is the reaction constant (or slope) 
representing the sensitivity of the given redox reaction to changes in substituents. Although there are only three points for each process, a high correlation coefficient is observed in the plot for each electrode reaction. As seen in the figure, the $\rho$ values range from $60-69 \mathrm{mV}$ for the two oxidations and first reduction, while a doubled $\rho$ value of $132 \mathrm{mV}$ is seen for the second reduction. The increased $\rho$ value for the second reduction is rather large for a metal-centered redox process and can be rationalized by an electron transfer at a site near the meso-phenyl ring of the DPP ligand, forming a substituent-centered radical, for example. ${ }^{34}$

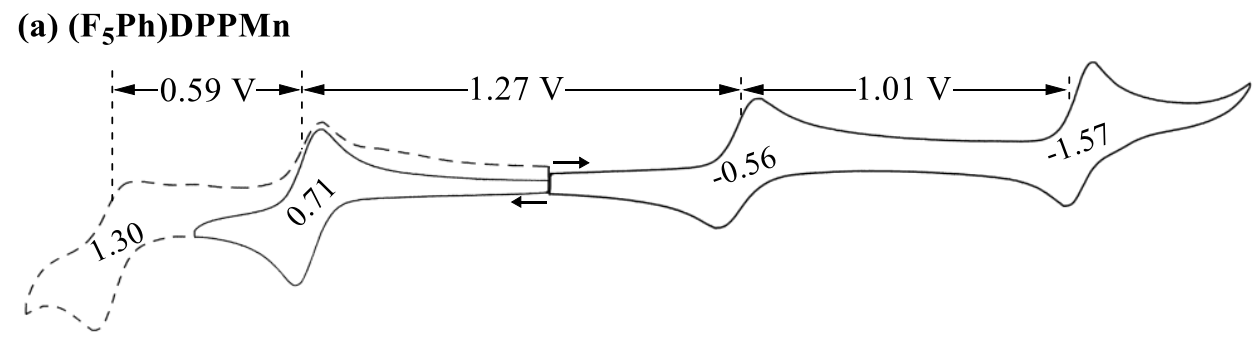

\section{(b) (Ph)DPPMn}

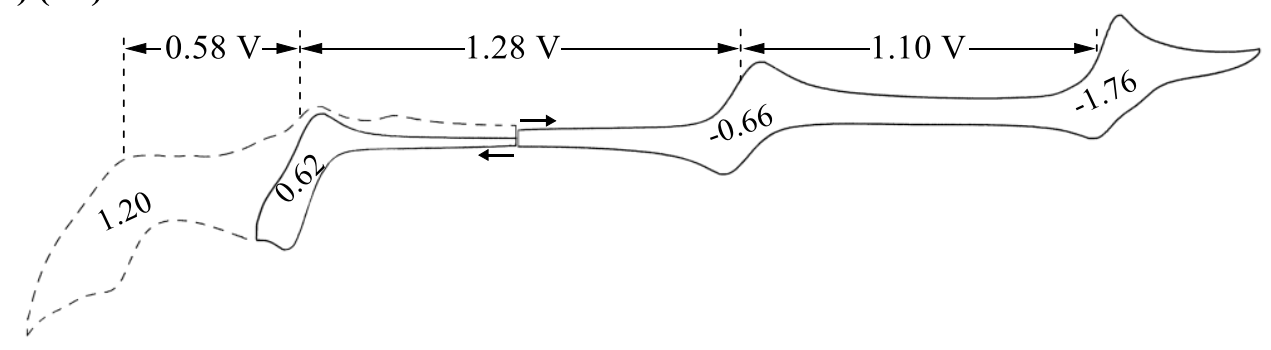

(c) (Mes)DPPMn

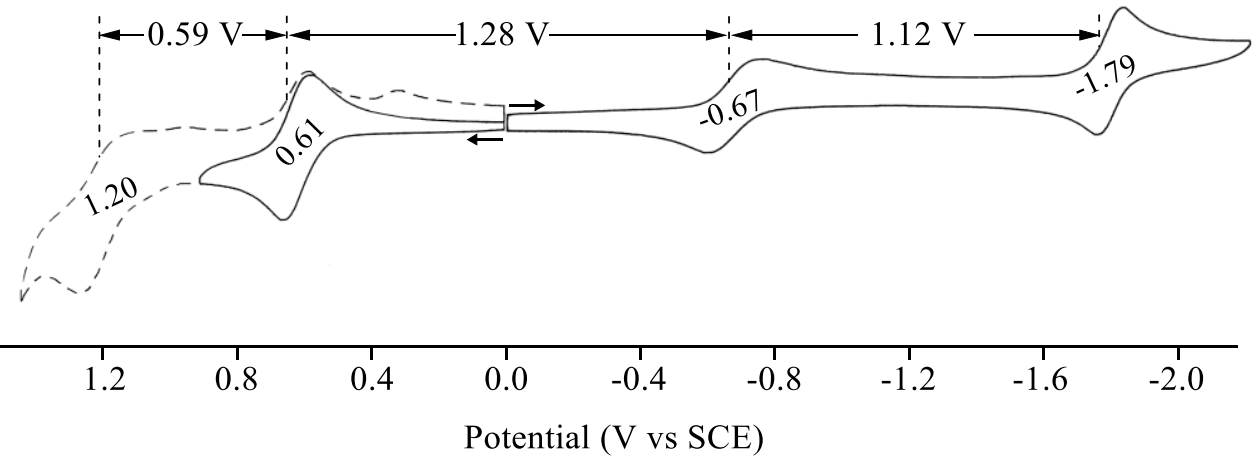

Figure 1. Cyclic voltammograms of (a) $\left(\mathrm{F}_{5} \mathrm{Ph}\right) \mathrm{DPPMn}$, (b) (Ph)DPPMn and (c) (Mes)DPPMn at $10^{-3} \mathrm{M}$ in $\mathrm{CH}_{3} \mathrm{CN}$ containing $0.1 \mathrm{M} \mathrm{TBAPF}_{6}$. Scan rate $=0.1 \mathrm{~V} / \mathrm{s}$. 
Table 1. Halfwave potentials ( $\mathrm{V} v s \mathrm{SCE})$ and anodic to cathodic peak separations $\left(\Delta E_{\mathrm{p}}\right)$ for reduction and oxidation of (Ar)DPPMn in $\mathrm{CH}_{3} \mathrm{CN}$ containing $0.1 \mathrm{M} \mathrm{TBAPF}_{6}$. Scan rate $=0.1 \mathrm{~V} / \mathrm{s}$.

\begin{tabular}{|c|c|c|c|c|c|}
\hline \multirow[b]{2}{*}{$\sigma$} & \multirow[b]{2}{*}{$\mathrm{Ar}$} & \multicolumn{2}{|c|}{ Ligand Oxidation } & \multirow{2}{*}{$\begin{array}{r}\left(\mathrm{Mn}^{\mathrm{III} /} / \mathrm{Mn}^{\mathrm{II}}\right) \\
E_{1 / 2}\left(\Delta E_{\mathrm{p}}\right)\end{array}$} & \multirow{2}{*}{$\begin{array}{c}\text { Ligand Reduction } \\
1^{\text {st }}\left(\Delta E_{\mathrm{p}}\right)\end{array}$} \\
\hline & & $2^{\text {nd }}\left(\Delta E_{\mathrm{p}}\right)$ & $1^{\text {st }}\left(\Delta E_{\mathrm{p}}\right)$ & & \\
\hline 1.22 & $\mathrm{~F}_{5} \mathrm{Ph}$ & $1.30(0.08)$ & $0.71(0.08)$ & $-0.56(0.08)$ & $-1.57(0.08)$ \\
\hline 0.00 & $\mathrm{Ph}$ & $1.20(0.10)$ & $0.62(0.10)$ & $-0.66(0.12)$ & $-1.76(0.06)$ \\
\hline-0.51 & Mes & $1.20(0.10)$ & $0.61(0.08)$ & $-0.67(0.14)$ & $-1.79(0.08)$ \\
\hline
\end{tabular}

To confirm the site of electron transfer, spectral changes were monitored during the first oxidation and first reduction of the three (Ar)DPPMn complexes in $\mathrm{CH}_{3} \mathrm{CN}$ containing $0.1 \mathrm{M} \mathrm{TBAPF}$. The initial and final spectra are shown in Figures 2 and 3, respectively. As seen in Figure 2 for oxidation, the initial $\mathrm{UV}$-vis spectrum in $\mathrm{CH}_{3} \mathrm{CN}$ before the application of a controlled potential is characterized by two major absorptions, an intense high energy band at 310-317 $\mathrm{nm}$ and a broad visible band with similar intensity located between $668-695 \mathrm{~nm}$. There is also a less intense visible band centered around $\sim 450 \mathrm{~nm}$ for each complex. Upon application of a controlled oxidizing potential of 0.8 to $1.0 \mathrm{~V}$, both major bands decrease in intensity as new, well defined near-IR (NIR) bands appear. These bands are located at 874 and $979 \mathrm{~nm}$ for ( $\left.\mathrm{F}_{5} \mathrm{Ph}\right) \mathrm{DPPMn}, 861$ and $974 \mathrm{~nm}$ for (Ph)DPPMn and 851 and $977 \mathrm{~nm}$ for (Mes)DPPMn. Four isosbestic points are also seen in each set of spectral changes in Figure 2, indicating the lack of a spectrally detectable intermediate upon going from (Ar)DPPMn ${ }^{\mathrm{III}}$ to $\left[(\mathrm{Ar}) \mathrm{DPP}^{\bullet} \mathrm{Mn}^{\mathrm{III}}\right]^{+}$. In addition, the overall spectral pattern for the oxidation products in Figure 2 are nearly identical to what was reported by Aukauloo, Andrioletti and coworkers where formation of a $\pi$-cation radical was assigned for the $\left(\mathrm{F}_{5} \mathrm{Ph}\right) \mathrm{DPPMn}$ complex under the same solution conditions and confirmed by ESR after the first one-electron abstraction. ${ }^{10}$

Further evidence for the assigned ligand-centered oxidation comes from the calculated Muliken spin densities of singly oxidized $\left[(\mathrm{Ph}) \mathrm{DPP}^{\bullet} \mathrm{Mn}^{\mathrm{III}}\right]^{+}$(Figure S2) which show an antiferromagnetically coupled $\mathrm{Mn}^{\mathrm{III}}$-ligand radical complex, similar to that reported for a structurally related [DPPMn $\left.{ }^{\mathrm{III}}\right]^{+}$complex containing one methanol axial ligand computed by Thomas and coworkers. ${ }^{12}$ 
(a) $\left(\mathbf{F}_{5} \mathbf{P h}\right)$ DPPMn

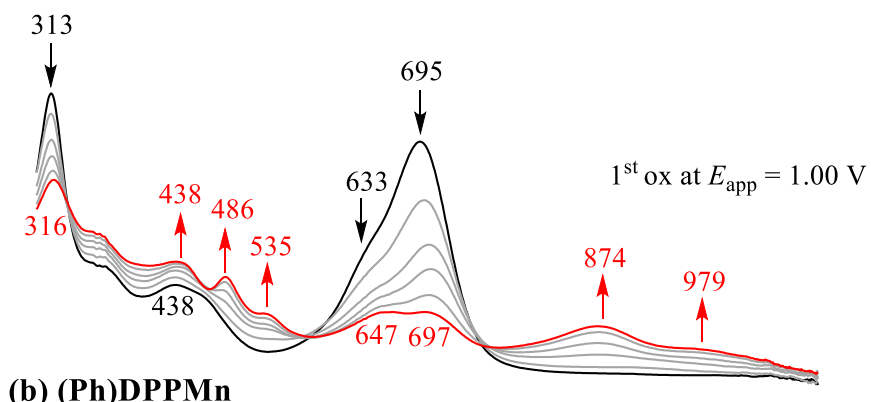

(b) (Ph)DPPMn

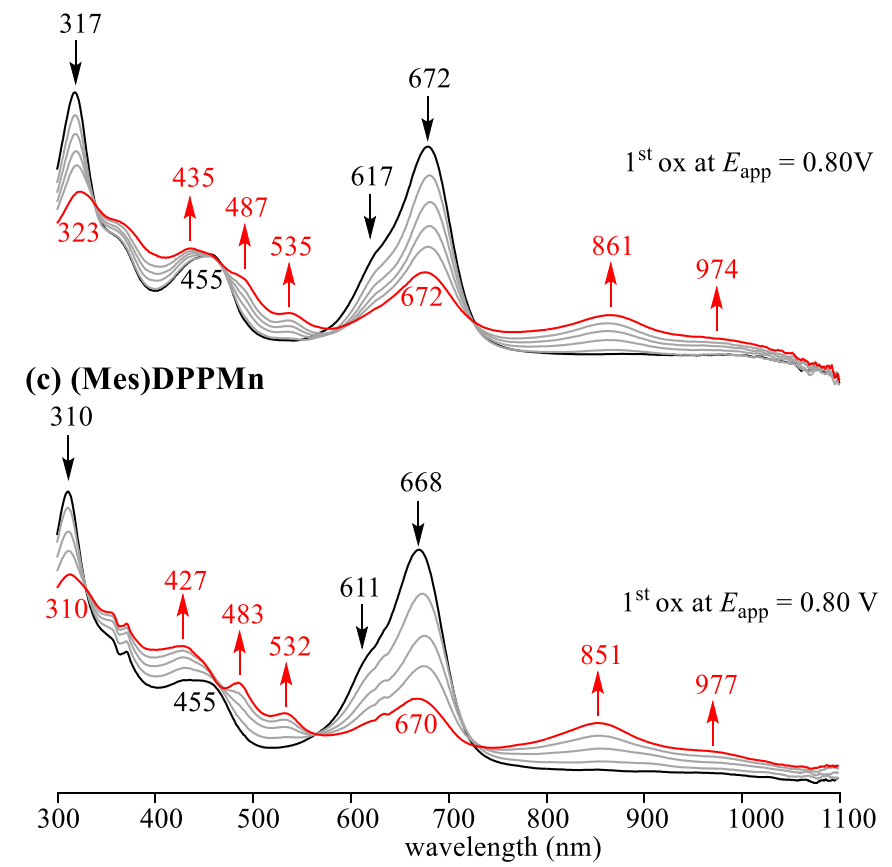

Figure 2. UV-vis spectral changes during the first one-electron oxidation of (a) $\left(\mathrm{F}_{5} \mathrm{Ph}\right) \mathrm{DPPMn}$, (b) ( $\mathrm{Ph}$ )DPPMn and (c) (Mes)DPPMn in $\mathrm{CH}_{3} \mathrm{CN}$ containing $0.1 \mathrm{M}$ TBAPF .

The measured spectral changes for the three (Ar)DPPMn complexes under a controlled reducing potential are shown in Figure 3 where the overall spectral envelopes of the neutral reactant and singly reduced products are quite similar to each other. The major visible band of (Ar)DPPMn, located at $695 \mathrm{~nm}$ $\left(\mathrm{Ar}=\mathrm{F}_{5} \mathrm{Ph}\right), 672 \mathrm{~nm}(\mathrm{Ar}=\mathrm{Ph})$ or $669 \mathrm{~nm}(\mathrm{Ar}=\mathrm{Mes})$, is blue-shifted to 633, 616 or $612 \mathrm{~nm}$ upon reduction and is increased in intensity as seen in the figure. It should also be noted that the wavenumber of the less intense visible band for both $\mathrm{Mn}^{\mathrm{III}}$ and electroreduced $\mathrm{Mn}^{\mathrm{II}}$ products, as well as the NIR band of the singly oxidized [(Ar)DPP• $\left.\mathrm{Mn}^{\mathrm{III}}\right]^{+}$compounds are all monotonically blue shifted upon going from the complex containing the electron withdrawing $\mathrm{F}_{5} \mathrm{Ph}$ aryl group to the complex containing an electron-donating 
mesityl meso-substituent and these values can also be correlated to the Hammett substituent constant as shown in Figure S3.

(a) $\left(\mathrm{F}_{5} \mathrm{Ph}\right) \mathrm{DPPMn}$
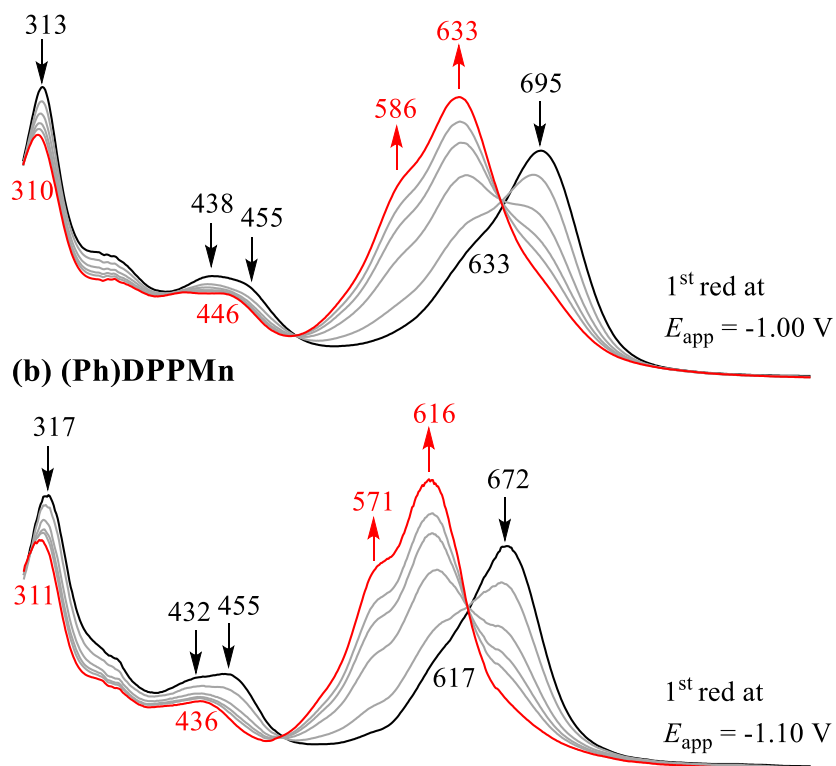

(c) (Mes)DPPMn

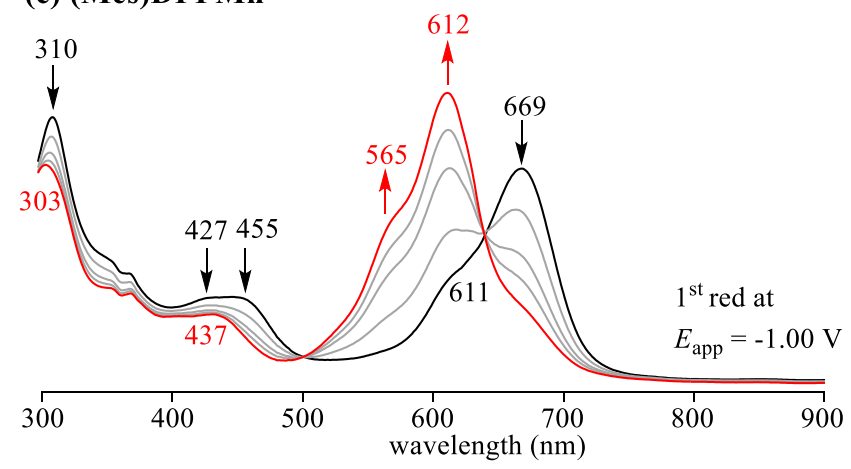

Figure 3. UV-vis spectral changes associated with the first reduction of (a) ( $\left.\mathrm{F}_{5} \mathrm{Ph}\right) \mathrm{DPPMn}$, (b) ( $\left.\mathrm{Ph}\right) \mathrm{DPPMn}$ and (c) (Mes)DPPMn in $\mathrm{CH}_{3} \mathrm{CN}$ containing $0.1 \mathrm{M}$ TBAPF .

The magnitude of the wavelength shift upon reduction amounts $62-56 \mathrm{~nm}$ as measured by the difference in $\lambda$ for the visible band of the neutral and singly reduced product. A similar overall spectral change and nearly identical $67 \mathrm{~nm}$ blue shift of the visible band was previously reported for the metalcentered reduction of $\left(\mathrm{F}_{5} \mathrm{Ph}\right) \mathrm{DPPCo}{ }^{\mathrm{III}}(\mathrm{Py})_{2}$ to $\left[\left(\mathrm{F}_{5} \mathrm{Ph}\right) \mathrm{DPPCo}^{\mathrm{II}}\right]^{-}$in pyridine containing $0.1 \mathrm{M} \mathrm{TBAClO}_{4}$. A direct comparison of the spectral changes associated with the metal-centered reduction for $\left(\mathrm{F}_{5} \mathrm{Ph}\right) \mathrm{DPPM}$ and $(\mathrm{Ph}) \mathrm{DPPM}$, where $\mathrm{M}=\mathrm{Mn}$ or $\mathrm{Co}$, in pyridine/ $\mathrm{TBAClO}_{4}$ is given in Figure $\mathrm{S} 4$. Moreover, the final 
spectral envelope of singly reduced [(Ar)DPPMn $\left.{ }^{\mathrm{II}}\right]^{-}$is nearly identical to that of electrogenerated $\left[(\mathrm{Ar}) \mathrm{DPPCu} \mathrm{u}^{\mathrm{II}}\right]^{-}$or $\left[(\mathrm{Ar}) \mathrm{DPPCo}^{\mathrm{II}}\right]^{-}$, both of which contain trianionic macrocycles with intact $\pi$ systems. $^{13,20}$ The nearly identical spectral changes for the $\mathrm{Co}^{\mathrm{III/II}}$ process in reference 20 and the assigned $\mathrm{Mn}^{\mathrm{III} / \mathrm{II}}$ redox reaction in the current study, as well as the similarity in spectra between the singly reduced DPP complexes of $\mathrm{Mn}, \mathrm{Cu}^{13}$ and $\mathrm{Co}^{20}$ strongly suggests a metal-centered reduction of the (Ar)DPPMn compounds, as described by eq 3 .

$$
(\mathrm{Ar}) \mathrm{DPPMn}^{\mathrm{III}}+\mathrm{e}^{-} \rightleftharpoons\left[(\mathrm{Ar}) \mathrm{DPPMn}^{\mathrm{II}}\right]^{-}
$$

Additional evidence for assignment of a metal-centered reduction as shown in eq 3 is given by a comparison between the spectrum of singly reduced $\left(\mathrm{F}_{5} \mathrm{Ph}\right) \mathrm{DPPMn}{ }^{\mathrm{III}}$ and the analogous boron(III) pentafluorophenyldipyrrin-bisphenol derivative, $\left(\mathrm{F}_{5} \mathrm{Ph}\right) \mathrm{DPPB}^{\mathrm{III}}$, the latter of which will not undergo a metal-centered reaction. Cyclic voltammograms of $\left(\mathrm{F}_{5} \mathrm{Ph}\right) \mathrm{DPPMn}^{\mathrm{III}}$ and $\left(\mathrm{F}_{5} \mathrm{Ph}\right) \mathrm{DPPB}{ }^{\mathrm{III}}$ are given in Figure 4 along with the UV-visible spectral changes measured during the first electron addition in $\mathrm{CH}_{3} \mathrm{CN}$ containing $0.1 \mathrm{M} \mathrm{TBAPF}_{6}$ and provide clear evidence for formation of a reduced $\pi$-ring system in the case of the boron derivative.

Although the potential for reduction of $\left(\mathrm{F}_{5} \mathrm{Ph}\right) \mathrm{DPPB}^{\mathrm{III}}\left(E_{1 / 2}=-0.63 \mathrm{~V}\right)$, is nearly identical to that of $\left(\mathrm{F}_{5} \mathrm{Ph}\right) \mathrm{DPPMn}\left(E_{1 / 2}=-0.56 \mathrm{~V}\right)$, the spectral changes associated with the first reduction of the two compounds are quite different. The major absorption bands of neutral $\left(\mathrm{F}_{5} \mathrm{Ph}\right) \mathrm{DPPB}{ }^{\mathrm{III}}$ at 313 and $640 \mathrm{~nm}$ decrease in intensity upon the application of a controlled reducing potential as three new absorptions grow in at 418,531 and $706 \mathrm{~nm}$, a result which is quite different than that for reduction of $\left(\mathrm{F}_{5} \mathrm{Ph}\right) \mathrm{DPPMn}$ (bottom of Figure 4a). The reduced intensity of the absorptions for the singly reduced [( $\left.\left.\mathrm{F}_{5} \mathrm{Ph}\right) \mathrm{DPP}^{\bullet} \mathrm{B}^{\mathrm{III}}\right]^{-}$product, as compared to the neutral species, is indicative of a break in the $\pi$ conjugation of the ligand and an electron addition to the conjugated macrocycle as described by eq 4 . This contrasts significantly with what is seen for the homologous manganese reduction product which has no characteristic bands of an anion radical.

$$
\left(\mathrm{F}_{5} \mathrm{Ph}\right) \mathrm{DPPB}^{\mathrm{III}}+\mathrm{e}^{-} \rightleftharpoons\left[\left(\mathrm{F}_{5} \mathrm{Ph}\right) \mathrm{DPP}^{\bullet} \mathrm{B}^{\mathrm{III}}\right]^{-}
$$

The nearly identical reduction potentials of -0.56 and $-0.63 \mathrm{~V}$ for the two $\left(\mathrm{F}_{5} \mathrm{Ph}\right) \mathrm{DPPM}$ complexes $\left(\mathrm{M}=\mathrm{Mn}^{\mathrm{III}}\right.$ or $\left.\mathrm{B}^{\mathrm{III}}\right)$, with different sites of electron transfer might suggest a possible intramolecular electron 
transfer (IMET) in the case of the manganese(III) compounds, i.e. a process where the electron addition first occurs at the DPP ligand $\pi$ orbitals and is subsequently transferred to the manganese(III) center ultimately giving [(Ar)DPPMn $\left.{ }^{\mathrm{II}}\right]^{-}$as a final product.
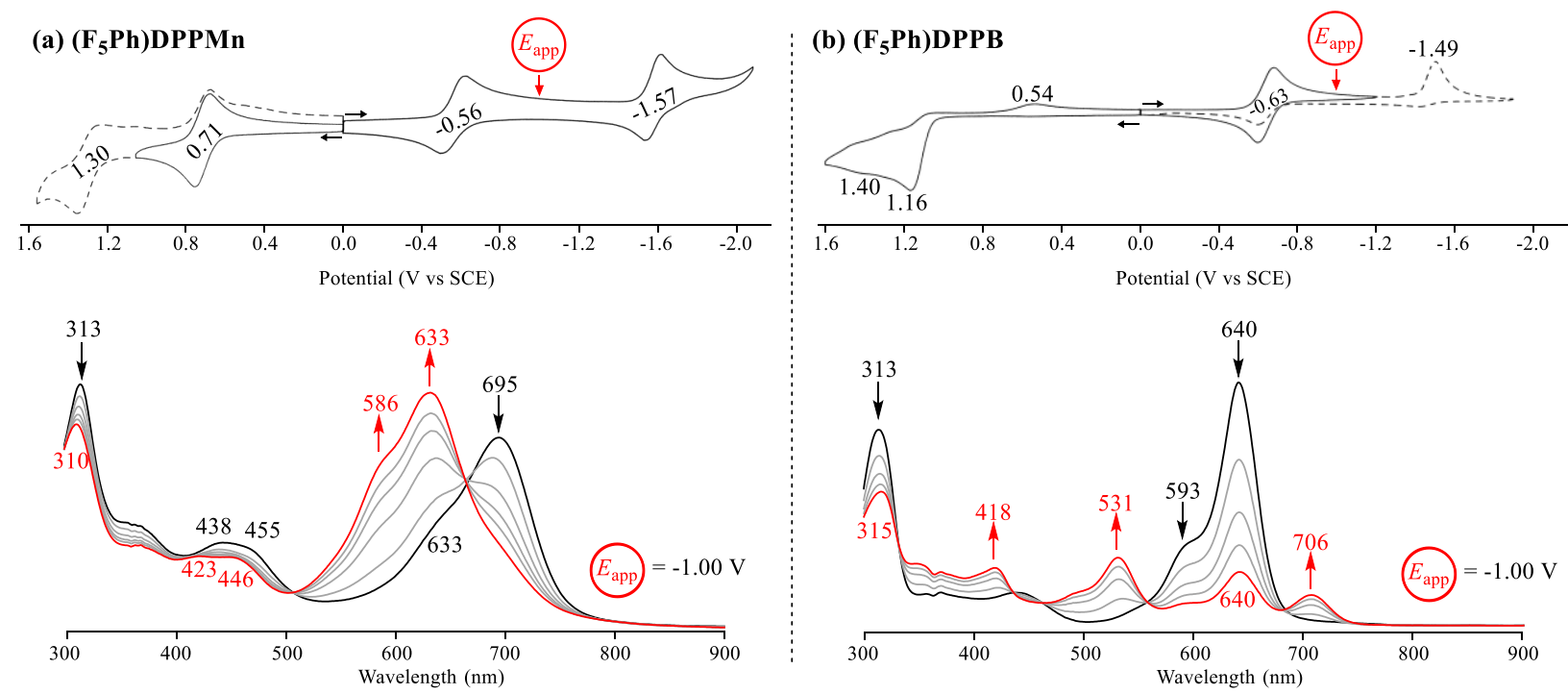

Figure 4. Cyclic voltammograms and spectral changes associated with the first electron addition to (a) $\left(\mathrm{F}_{5} \mathrm{Ph}\right) \mathrm{DPPMn}$ and $(\mathrm{b})\left(\mathrm{F}_{5} \mathrm{Ph}\right) \mathrm{DPPB}$ in $\mathrm{CH}_{3} \mathrm{CN}$ containing $0.1 \mathrm{M} \mathrm{TBAPF}_{6}$.

Solvent Effect on Electrochemical Behavior. As described above, and also in the literature, 10, 12 the first oxidation of ( $\mathrm{Ar}$ )DPPMn in $\mathrm{CH}_{3} \mathrm{CN}$ or $\mathrm{CH}_{2} \mathrm{Cl}_{2}$ involves the $\pi$-ring system. However, given the known metal-centered oxidation of $\mathrm{Mn}(\mathrm{III})$ corroles $^{18,21,35,36}$ and the emerging DPP-corrole analogy supported by numerous reports of transition metal DPP complexes ${ }^{13,20,22-24}$ we had anticipated that a change of the electrochemical solvent/supporting electrolyte conditions might lead to changes in both the oxidation potential and the site of electron transfer. We also wondered if one might observe a solvent dependent change in the site of reduction, since the same corroles known to undergo a facile metal-centered $\mathrm{Mn}^{\mathrm{III} / \mathrm{IV}}$ process, were characterized as undergoing either a quite difficult reduction at the $\mathrm{Mn}^{\mathrm{III}}$ center in nonaqueous media or no reduction at all, in which case the first electron addition would be assigned as formation of a $\mathrm{Mn}^{\mathrm{III}} \pi$-anion radical. ${ }^{31,35,36}$

In order to investigate the possible 'tuning' of the $\mathrm{Mn}^{\mathrm{III}} \mathrm{DPP}$ redox potentials and site of electron transfer, six different nonaqueous solvents were selected for the electrochemical characterization of (Ar)DPPMn in solutions containing $0.1 \mathrm{M} \mathrm{TBAPF}_{6}$ as supporting electrolyte. A summary of the measured 
oxidation and reduction potentials for $(\mathrm{Ph}) \mathrm{DPPMn}$ in these solvents containing $0.1 \mathrm{M} \mathrm{TBAPF}_{6}$ is given in Table 2 and examples of cyclic voltammograms are shown in Figure 5, where three types of current-voltage curves are seen for reduction. The first is in $\mathrm{CH}_{2} \mathrm{Cl}_{2}$ and $\mathrm{C}_{2} \mathrm{H}_{4} \mathrm{Cl}_{2}$ where the reduction peak is broad and no clear reoxidation peak is observed, perhaps due to the formation of dimers in solution as seen in the solid state $^{10}$ and also in the gas phase as seen by the ESI-MS results in Figures S4 and S5. The second type of current-voltage curve is obtained in pyridine (Py) and DMSO where the separation between the cathodic and anodic peaks, $E_{\mathrm{pc}}$ and $E_{\mathrm{pa}}$ values ranges from 280 to $320 \mathrm{mV}$ suggesting a slow (quasireversible) ${ }^{37}$ electron transfer with possible coupled chemical reactions. More rapid electron transfers are also seen in $\mathrm{CH}_{3} \mathrm{CN}$ and $\mathrm{CH}_{3} \mathrm{OH}$, as indicated by the moderate separation of 120 and $180 \mathrm{mV}$ between the $E_{\mathrm{pc}}$ and $E_{\mathrm{pa}}$ values, and in these two solvents the cathodic and anodic peaks are well-defined indicating the absence of coupled chemical reactions on the timescale of the electrochemical measurement. Although the shape of the current-voltage curves and separations between $E_{\mathrm{pc}}$ and $E_{\mathrm{pa}}$ for reduction are clearly solvent dependent, the oxidations are reversible in each investigated solvent as seen in the figure and also in Table 2 which lists $\Delta E_{\mathrm{p}}$ for each redox process.

The quasireversible (slow) electron transfer for the $\mathrm{Mn}^{\mathrm{III} / \mathrm{II}}$ reduction process in $\mathrm{CH}_{2} \mathrm{Cl}_{2}$ and $\mathrm{C}_{2} \mathrm{H}_{4} \mathrm{Cl}_{2}$ (as indicated by a $\Delta E_{\mathrm{p}} \gg>60 \mathrm{mV}$ and the lack of a well-defined reoxidation) and the faster electron transfer for the first oxidation under the same solution conditions $\left(\Delta E_{\mathrm{p}}=80\right.$ to $\left.100 \mathrm{mV}\right)$ is consistent with not only the different sites of electron transfer (i.e. a ligand-centered oxidation and a metal-centered reduction) as assigned above but also the possible presence of a coupled chemical reaction on reduction. The larger $\Delta E_{\mathrm{p}}$ value associated with a slow metal-centered reduction is also consistent for what has been reported for the $\mathrm{Mn}^{\mathrm{III} / \mathrm{II}}$ process of many porphyrins ${ }^{38-40}$ and also other $\mathrm{Mn}^{\mathrm{III}}$ macrocycles. ${ }^{41-43}$ 
Table 2. Halfwave potentials ( $\mathrm{V} v s \mathrm{SCE}$ ) and anodic to cathodic peak separations $\left(\Delta E_{\mathrm{p}}\right)$ for reduction and oxidation of $(\mathrm{Ph}) \mathrm{DPPMn}$ in different solvents with $0.1 \mathrm{M} \mathrm{TBAPF}_{6}$.

\begin{tabular}{llllll}
\hline \multirow{2}{*}{ Solvent } & \multicolumn{2}{c}{ Ligand Oxidation } & & $\left(\mathrm{Mn}^{\mathrm{III}} / \mathrm{Mn}^{\mathrm{II}}\right)$ & Ligand Reduction \\
\cline { 2 - 3 } & $2^{\text {nd }}\left(\Delta E_{\mathrm{p}}\right)$ & $1^{\text {st }}\left(\Delta E_{\mathrm{p}}\right)$ & & $E_{1 / 2}\left(\Delta E_{\mathrm{p}}\right)$ & $1^{\text {st }}\left(\Delta E_{\mathrm{p}}\right)$ \\
\cline { 2 - 3 } \cline { 5 - 6 } $\mathrm{CH}_{2} \mathrm{Cl}_{2}$ & $1.25(0.10)$ & $0.68(0.10)$ & & $-0.79^{\mathrm{a}}$ & $\mathrm{b}$ \\
$\mathrm{C}_{2} \mathrm{H}_{4} \mathrm{Cl}_{2}$ & $1.27(0.10)$ & $0.69(0.10)$ & & $-0.82^{\mathrm{a}}$ & $\mathrm{b}$ \\
$\mathrm{Py}$ & $\mathrm{b}$ & $0.71(0.10)$ & & $-0.78(0.32)$ & $-1.76(0.10)$ \\
$\mathrm{DMSO}$ & $\mathrm{b}$ & $0.64(0.08)$ & & $-0.70(0.28)$ & $-1.72(0.08)$ \\
$\mathrm{CH}_{3} \mathrm{OH}$ & $\mathrm{b}$ & $0.52(0.08)$ & & $-0.75(0.18)$ & $\mathrm{b}$ \\
$\mathrm{CH}_{3} \mathrm{CN}$ & $1.20(0.10)$ & $0.62(0.10)$ & & $-0.66(0.12)$ & $-1.76(0.08)$
\end{tabular}

${ }^{\mathrm{a}}$ Irreversible peak potential at scan rate of $0.1 \mathrm{~V} / \mathrm{s} .{ }^{\mathrm{b}}$ Reaction not observed due to limited solvent potential window.
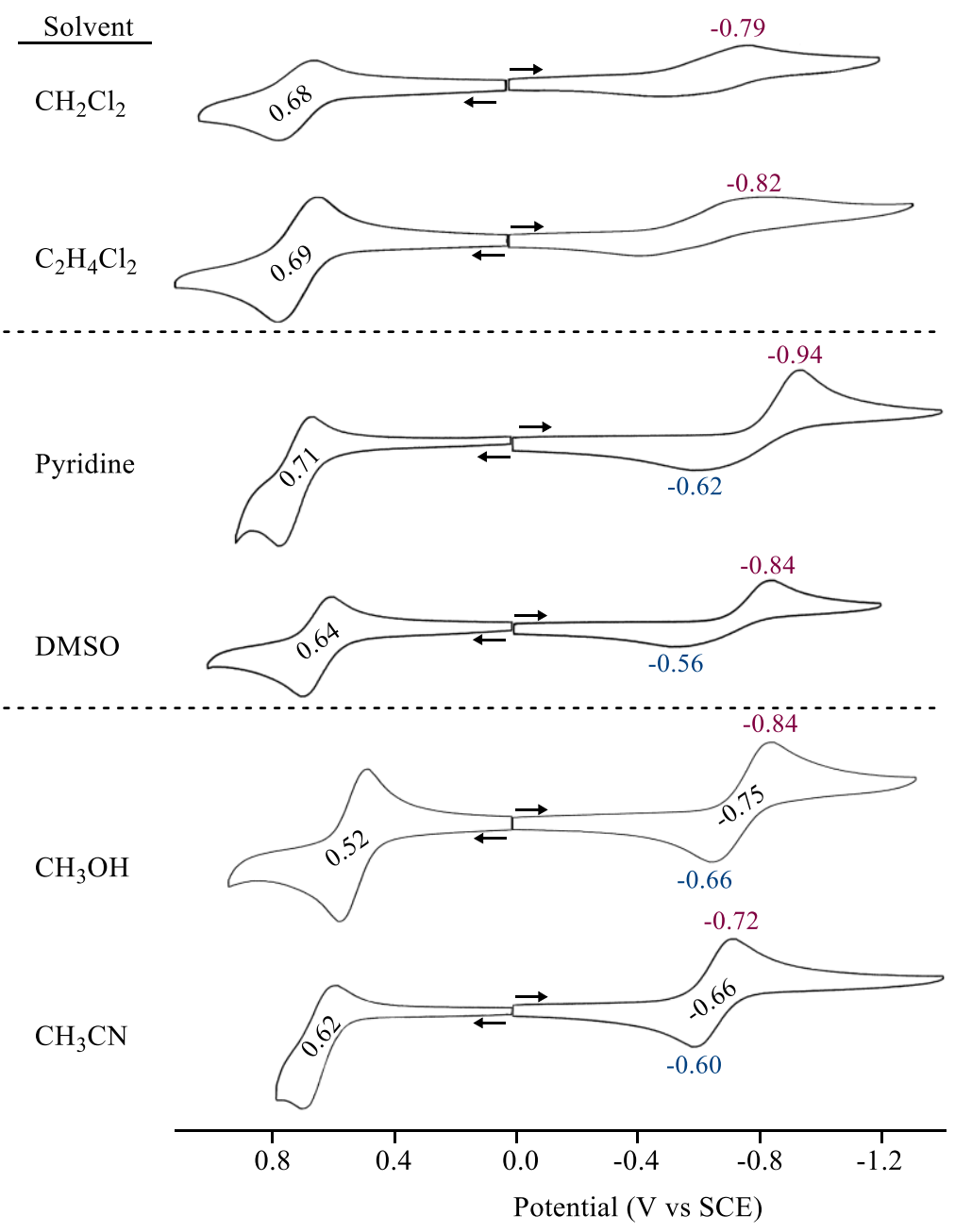

Figure 5. Cyclic voltammograms of ( $\mathrm{Ph}) \mathrm{DPPMn}$ at $10^{-3} \mathrm{M}$ comparing the first reduction and first oxidation in six different nonaqueous solvents containing 0.1 $\mathrm{M} \mathrm{TBAPF}_{6}$. Scan rate $=0.1 \mathrm{~V} / \mathrm{s}$. 
It is also worth noting that, with the exception of $\mathrm{CH}_{2} \mathrm{Cl}_{2}$ and $\mathrm{C}_{2} \mathrm{H}_{4} \mathrm{Cl}_{2}$, the cathodic peak currents for the first reduction $\left(i_{\mathrm{pc}}\right)$ are essentially the same as the anodic peak currents for the first oxidation $\left(i_{\mathrm{pa}}\right)$, consistent with the same number of electrons transferred in each step. Moreover, in the four solvents where a clear anodic reoxidation peak is observed for the quasireversible first reduction (Py, DMSO, $\mathrm{CH}_{3} \mathrm{OH}$ and $\mathrm{CH}_{3} \mathrm{CN}$ ), a linear correlation between the donor number of the solvent and the separation between the $E_{\mathrm{pc}}$ and $E_{\mathrm{pa}}$ values exists as shown in Figure 6.

Regardless of the solvent and reversibility, each reduction of (Ar)DPPMn ${ }^{\mathrm{III}}$ is confirmed to involve a $\mathrm{Mn}^{\mathrm{III} / \mathrm{II}}$ redox couple as evidenced by the spectroelectrochemical data provided in Figure 7. A summary of this spectral data, including molar absorptivites for bands of the initial (Ph)DPPMn ${ }^{\mathrm{III}}$ spectra and the final $\left[(\mathrm{Ph}) \mathrm{DPPMn}^{\mathrm{II}}\right]^{-}$product are given in Table 3. In each solvent, a 50-68 nm blue shift of the major visible band is observed upon reduction and there is also a slight decrease in intensity of the broad visible band of the $\mathrm{Mn}^{\mathrm{II}}$ complex centered around $459-437 \mathrm{~nm}$.

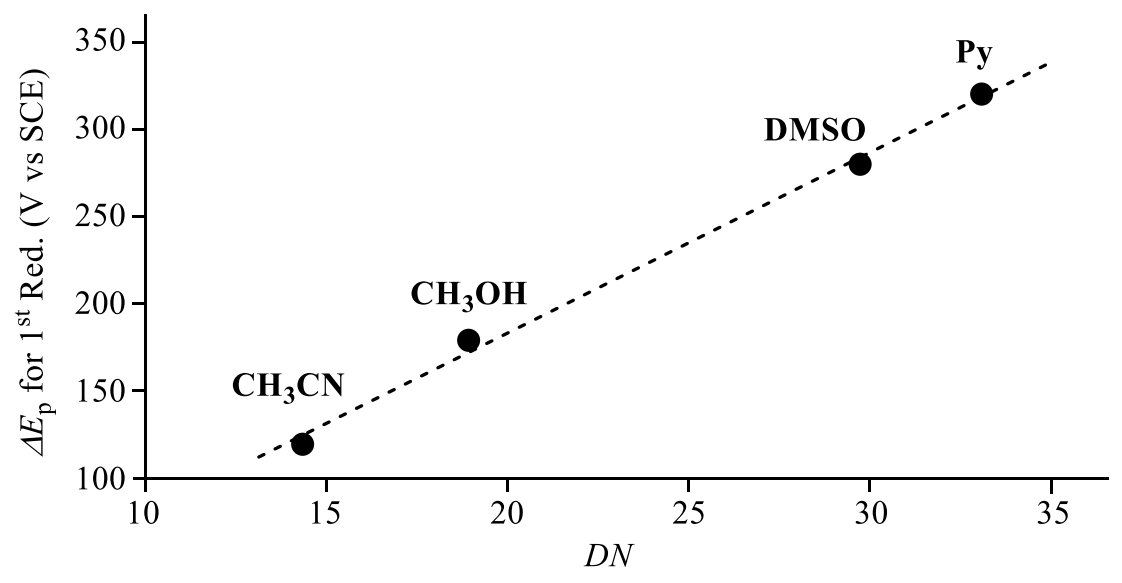

Figure 6. Plot $\Delta E_{\mathrm{p}}$ (as measured from the difference between $E_{\mathrm{pc}}$ and $E_{\mathrm{pa}}$ ) for the first reduction of $(\mathrm{Ph}) \mathrm{DPPMn}$ in different solvents containing 0.1 $\mathrm{M} \mathrm{TBAPF}_{6} v s$ the Gutmann Donor Number (DN) of the solvent. See voltammograms in Figure 5. 


\section{(a) $\mathrm{CH}_{2} \mathrm{Cl}_{2}$}

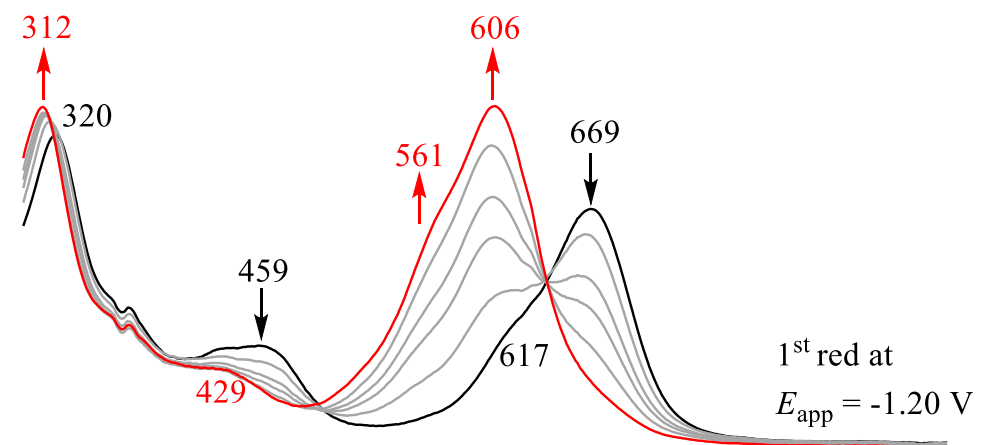

(b) Py

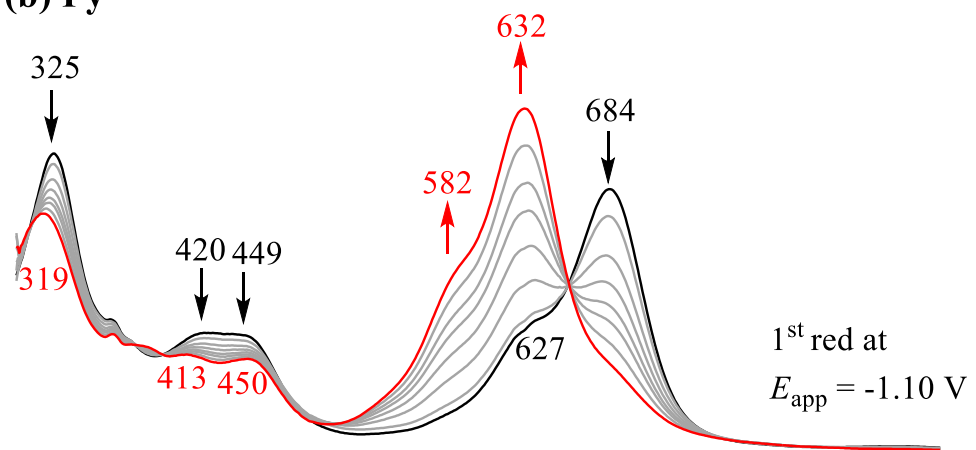

(c) DMSO

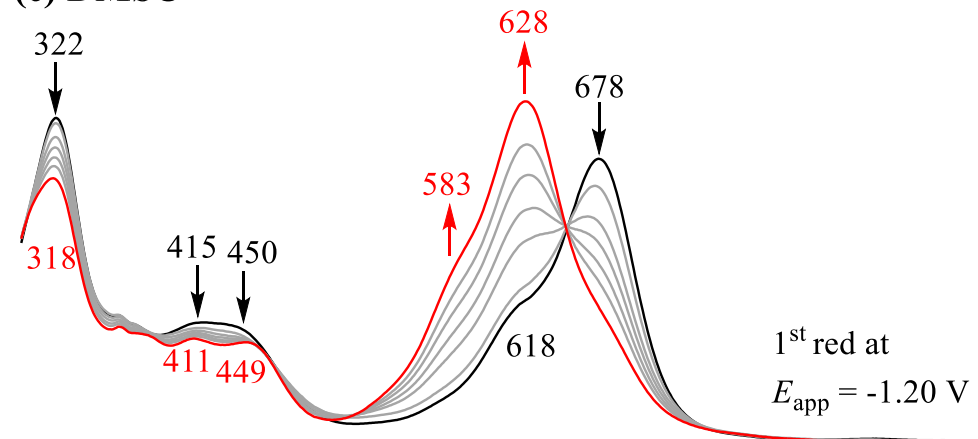

(d) $\mathrm{CH}_{3} \mathrm{OH}$

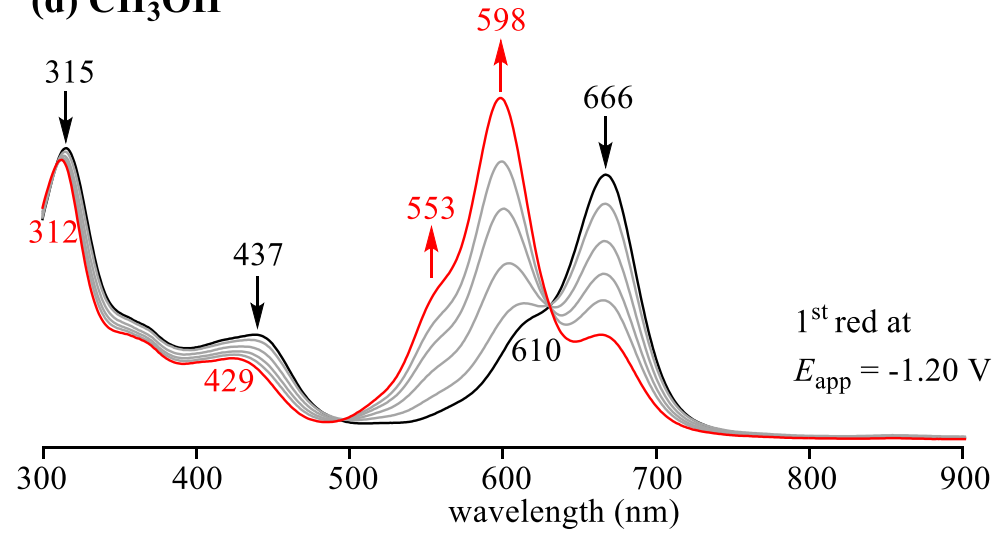

Figure 7. UV-vis spectral changes during controlled potential reduction of ( $\mathrm{Ph}$ )DPPMn in (a) $\mathrm{CH}_{2} \mathrm{Cl}_{2}$, (b) $\mathrm{Py}$, (c) DMSO and (d) $\mathrm{CH}_{3} \mathrm{OH}, 0.1 \mathrm{M} \mathrm{TBAPF}_{6}$. The spectra of the initial $\mathrm{Mn}^{\mathrm{III}}$ compounds are shown in black and that of the electroreduced $\mathrm{Mn}^{\mathrm{II}}$ complexes are in red. 
Table 3. UV-vis spectral data of $(\mathrm{Ph}) \mathrm{DPPMn}^{\mathrm{n}}(\mathrm{n}=\mathrm{III}$ or II $)\left(\sim 10^{-4} \mathrm{M}\right)$ in various solvents containing 0.1 M TBAPF .

\begin{tabular}{|c|c|c|c|c|c|c|c|}
\hline \multirow{2}{*}{$\begin{array}{l}\text { Ox. State } \\
\mathrm{Mn}^{\mathrm{III}}\end{array}$} & \multirow{2}{*}{$\begin{array}{l}\text { Solvent } \\
\mathrm{CH}_{2} \mathrm{Cl}_{2}\end{array}$} & \multirow{2}{*}{$\begin{array}{r}\beta^{\mathrm{a}} \\
0.00\end{array}$} & \multicolumn{5}{|c|}{$\lambda, \mathrm{nm}\left(\varepsilon \times 10^{-4}, \mathrm{M}^{-1} \cdot \mathrm{cm}^{-1}\right)^{\mathrm{b}}$} \\
\hline & & & $320(0.47)$ & & $459(0.20)$ & $617(0.24)$ & $669(0.36)$ \\
\hline & $\mathrm{C}_{2} \mathrm{H}_{4} \mathrm{Cl}_{2}$ & 0.00 & $321(1.20)$ & $428(0.61)$ & $458(0.47)$ & $619(0.41)$ & $671(0.90)$ \\
\hline & $\mathrm{CH}_{3} \mathrm{CN}$ & 0.31 & $317(1.60)$ & $432(0.50)$ & $455(0.61)$ & $617(0.52)$ & $674(1.06)$ \\
\hline & $\mathrm{CH}_{3} \mathrm{OH}$ & 0.62 & $315(2.13)$ & & $437(0.80)$ & $610(0.76)$ & $666(1.81)$ \\
\hline & Py & 0.64 & $325(2.46)$ & $420(0.95)$ & $449(0.85)$ & $627(0.88)$ & 684 (1.98) \\
\hline & DMSO & 0.76 & $322(2.39)$ & $415(0.81)$ & $450(0.67)$ & $618(0.93)$ & $678(1.97)$ \\
\hline \multirow[t]{6}{*}{$\mathrm{Mn}^{\mathrm{II}}$} & $\mathrm{CH}_{2} \mathrm{Cl}_{2}$ & 0.00 & $312(0.51)$ & & $429(0.10)$ & $561(0.30)$ & $606(0.51)$ \\
\hline & $\mathrm{C}_{2} \mathrm{H}_{4} \mathrm{Cl}_{2}$ & 0.00 & $317(1.02)$ & & $444(0.29)$ & $570(0.49)$ & $617(0.90)$ \\
\hline & $\mathrm{CH}_{3} \mathrm{CN}$ & 0.31 & $311(1.10)$ & & $436(0.40)$ & $571(0.80)$ & $616(1.37)$ \\
\hline & $\mathrm{CH}_{3} \mathrm{OH}$ & 0.62 & $312(1.91)$ & & $429(0.54)$ & $553(0.96)$ & $598(2.34)$ \\
\hline & Py & 0.64 & $319(1.79)$ & $413(0.75)$ & $450(0.71)$ & $582(1.33)$ & $632(2.50)$ \\
\hline & DMSO & 0.76 & $318(2.11)$ & $411(0.77)$ & 449 (0.74) & $583(1.39)$ & $628(2.63)$ \\
\hline
\end{tabular}

${ }^{\mathrm{a}} \beta$ scale of hydrogen bond acceptor basicities taken from ref. $44 .{ }^{\mathrm{b}} \varepsilon$ values were calculated based on the monomeric compound.

Correlations with Solvent Properties and Evidence of Dimerization in Solution. As seen in Table 3, a substantial decrease in molar absorptivity is observed for all bands of (Ph)DPPMn in $\mathrm{CH}_{2} \mathrm{Cl}_{2}$ or $\mathrm{C}_{2} \mathrm{H}_{4} \mathrm{Cl}_{2}$ containing $0.1 \mathrm{M} \mathrm{TBAPF}_{6}$ as compared to the other solvents. The solvent dependent phenomenon is best shown by the UV-visible spectra in Figure 8 which plots the molar absorptivity $(\varepsilon) v s$ wavelength for ( $\mathrm{Ph}$ )DPPMn in $\mathrm{CH}_{2} \mathrm{Cl}_{2}, \mathrm{CH}_{3} \mathrm{CN}$ and pyridine (Py). The marked decrease in absorptivity in the two noncoordinating solvents parallels the decreased currents for reduction as compared to what is seen in the other solvents (Figure 5) and can be rationalized by the presence of a homodimer as also observed in the solid state. ${ }^{10}$ Surprisingly, however, there is only a minor effect of dimerization on the position of the absorption bands and overall shape of the spectra, both of which are related to specific solvent properties as described on the following pages. 


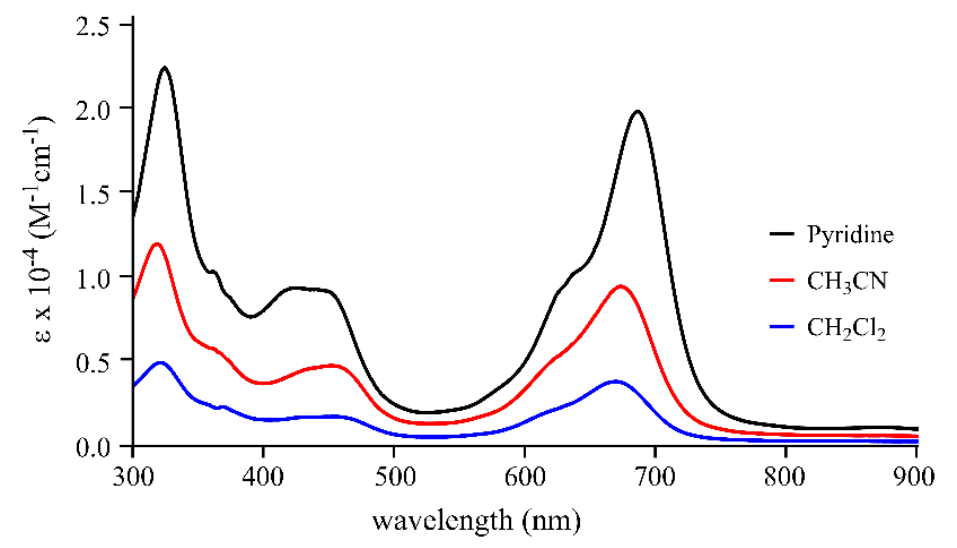

Figure 8. Normalized UV-vis spectra of neutral $(\mathrm{Ph}) \mathrm{DPPMn}^{\mathrm{III}}$ in Py (black line), $\mathrm{CH}_{3} \mathrm{CN}$ (red line) and $\mathrm{CH}_{2} \mathrm{Cl}_{2}$ (blue line), all containing $0.1 \mathrm{M} \mathrm{TBAPF}_{6}$.

Again, with the exception of the two noncoordinating solvents, $\mathrm{CH}_{2} \mathrm{Cl}_{2}$ and $\mathrm{C}_{2} \mathrm{H}_{4} \mathrm{Cl}_{2}$, where dimerization and/or aggregation is known to occur for related manganese(III) $\mathrm{N}_{2} \mathrm{O}_{2}$-type complexes with Schiff base ligands. ${ }^{43,45}$ the energy of the visible band in wavenumbers (v) systematically decreases with decrease in polarity of the solvent, as measured by the Dimroth-Reichardt $\left(\mathrm{E}_{\mathrm{T}}\right)$ parameter. ${ }^{46}$ This correlation is shown by the plot in Figure 9 for both $(\mathrm{Ph}) \mathrm{DPPMn}^{\mathrm{III}}$ and $\left[(\mathrm{Ph}) \mathrm{DPPMn}^{\mathrm{II}}\right]^{-}$where the $\mathrm{E}_{\mathrm{T}}$ values range from 40.2 for Py to 55.5 for $\mathrm{CH}_{3} \mathrm{OH}$. The slope of $v$ s $\mathrm{E}_{\mathrm{T}}$ plot is $25.4 \mathrm{~cm}^{-1} / \mathrm{E}_{\mathrm{T}}$ for the neutral $\mathrm{Mn}^{\mathrm{III}}$ species and $60.9 \mathrm{~cm}^{-1} / \mathrm{E}_{\mathrm{T}}$ for the reduced $\mathrm{Mn}^{\mathrm{II}}$ species. Similar negative solvatochromic effects have been described by Reichardt, ${ }^{47}$ notably for BODIPY dyes ${ }^{48}$ and suggests that the ground state is stabilized by polar solvents. An additional correlation, which includes $\mathrm{CH}_{2} \mathrm{Cl}_{2}$ and $\mathrm{C}_{2} \mathrm{H}_{4} \mathrm{Cl}_{2}$, could also be established between the wavenumber corresponding to the visible band of the neutral $\mathrm{Mn}^{\mathrm{III}}$ complex and the corresponding blueshifted visible band of the singly reduced $\mathrm{Mn}^{\mathrm{II}}$ complex in the six nonaqueous solvents. This correlation is given in Figure 10 and shows that largest difference in $v$ between visible bands of the neutral and singly reduced $(\mathrm{Ph}) \mathrm{DPPMn}$ complex is seen in $\mathrm{CH}_{3} \mathrm{OH}\left(\Delta v=1707 \mathrm{~cm}^{-1}\right)$ while the smallest $\Delta v$ occurs in pyridine (Py). Finally, a linear relationship exists between the molar absorptivity of the neutral or reduced compound and of the Kamlet-Taft parameter, $\beta$, which measures the solvent Hydrogen-Bond Acceptor (HBA) basicity (i.e. the ability of the solvent to accept a proton, or donate an electron pair in a solvent-to-solute hydrogen bond). This relationship is shown in Figure 11 for both the $\mathrm{Mn}^{\mathrm{III}}$ and electroreduced $\mathrm{Mn}^{\mathrm{II}}$ product in the six investigated solvents. 
The solvent dependent linear free energy relationships in Figures 6 and 9 clearly demonstrate that solvent-solute interaction is the driving force for the electrochemical behavior and spectroscopic properties of the investigated manganese dipyrrin bisphenols.
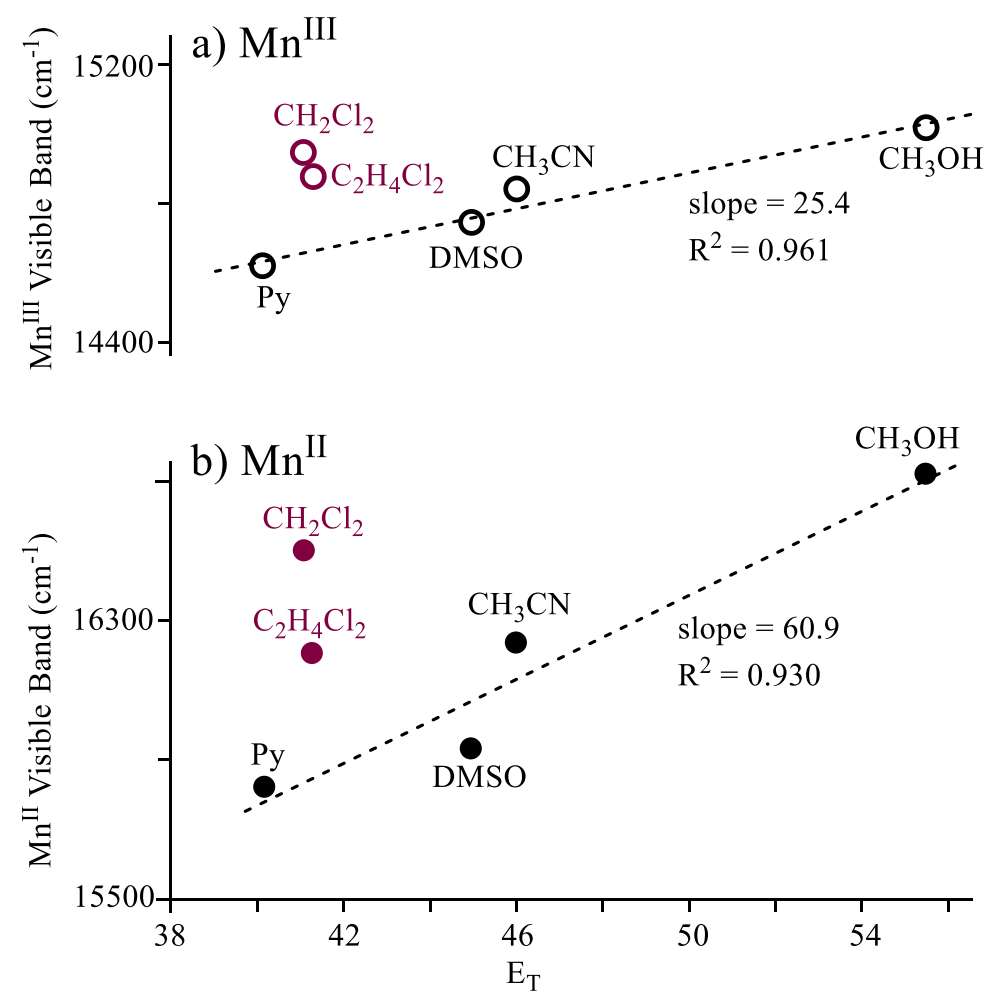

Figure 9. Wavenumber $\left(\mathrm{cm}^{-1}\right)$ of visible bands for a) neutral $(\mathrm{Ph}) \mathrm{DPPMn}{ }^{\mathrm{III}}$ and b) singly reduced $\left[(\mathrm{Ph}) \mathrm{DPPMn}^{\mathrm{II}}\right]^{-}$vs $\mathrm{E}_{\mathrm{T}}$ in different nonaqueous solvents.

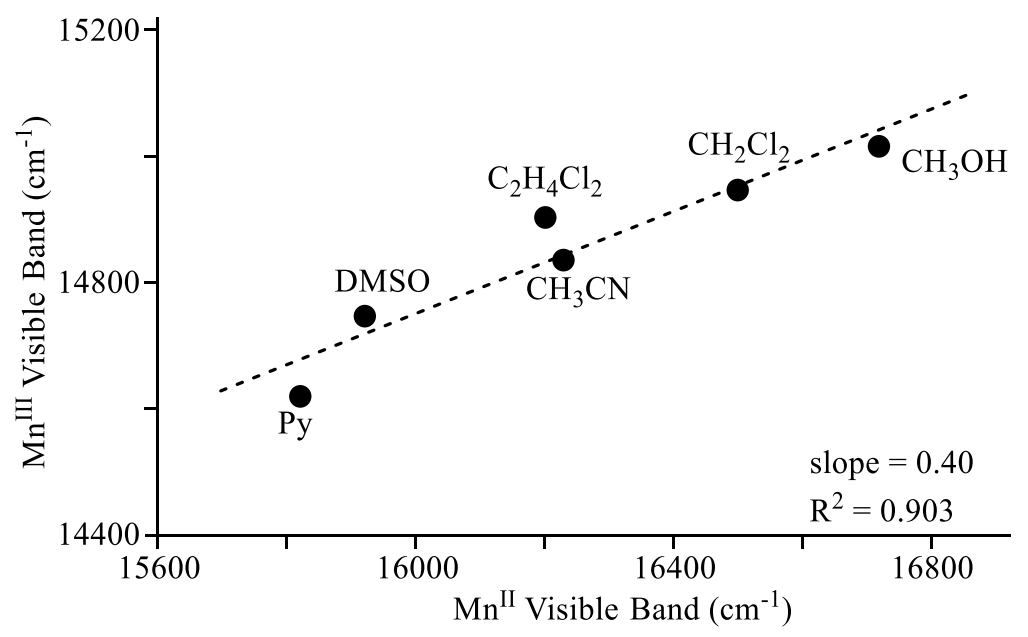

Figure 10. Wavenumber $\left(\mathrm{cm}^{-1}\right)$ of visible bands for neutral $(\mathrm{Ph}) \mathrm{DPPMn}^{\mathrm{III}} v s$ singly reduced [(Ph)DPPMn $\left.{ }^{\mathrm{II}}\right]^{-}$ in different nonaqueous solvents. 

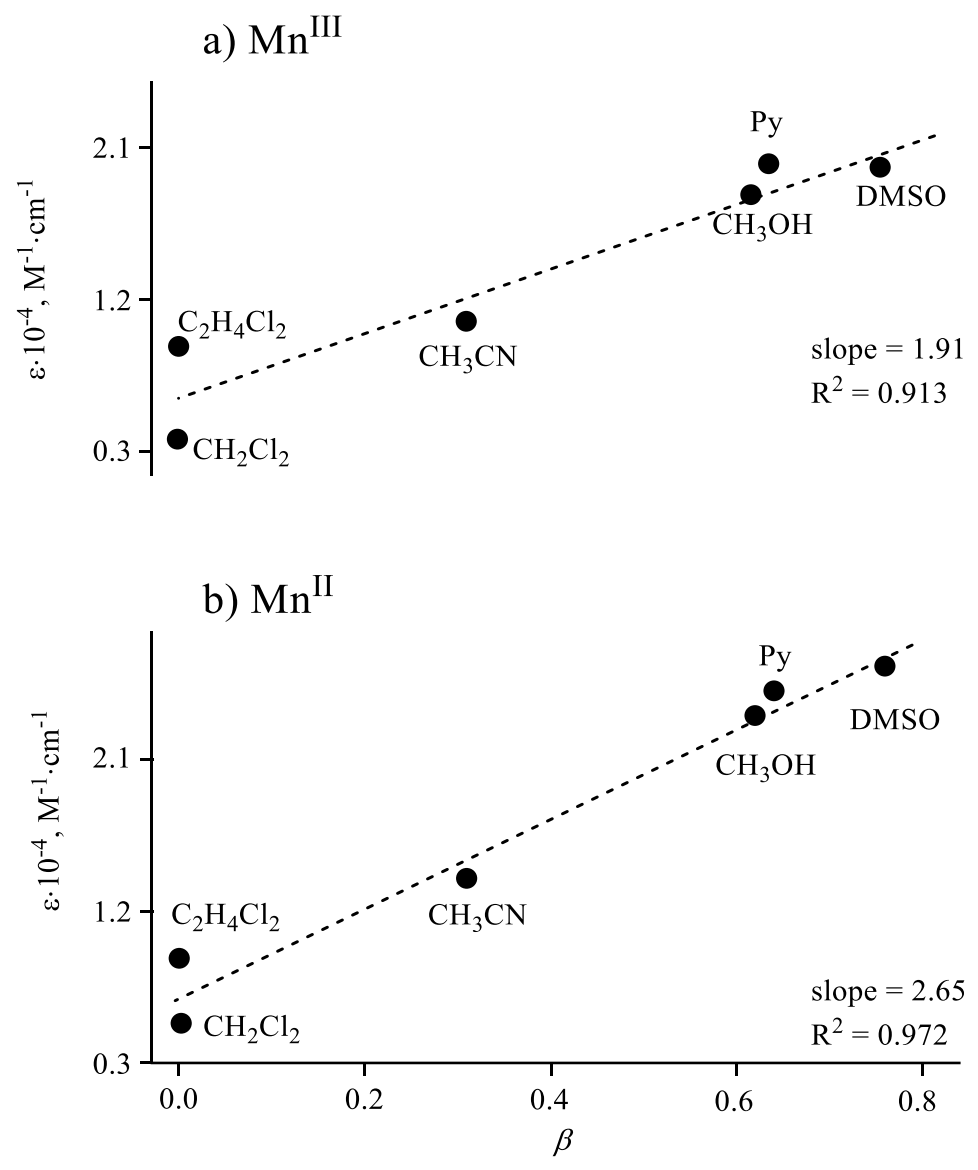

Figure 11. Molar absorptivities $\left(\varepsilon \times 10^{-4}\right)$ for a) $(\mathrm{Ph}) \mathrm{DPPMn}^{\mathrm{III}}$ and b) singly reduced $\left[(\mathrm{Ph}) \mathrm{DPPMn}{ }^{\mathrm{II}}\right]^{-}$of the most intense visible band $v$ s the Kamlet-Taft solvent parameter $(\beta)$.

The shift in molar absorptivity for the visible band of $\mathrm{Mn}^{\mathrm{III}}$ and $\mathrm{Mn}^{\mathrm{II}}$ with the $\beta$ solvent parameter (Figure 11) suggests that the dimer proposed to be present in $\mathrm{CH}_{2} \mathrm{Cl}_{2}$ and $\mathrm{C}_{2} \mathrm{H}_{4} \mathrm{Cl}_{2}$ can be dissociated by interaction with solvent molecules, giving monomeric (Ar)DPPMn via two possible pathways as shown schematically in Scheme 1. One path (Pathway A) involves an interaction with the two chelating oxygen atoms of the (Ar)DPP ligand while the other (Pathway B) involves an axial coordination to the manganese central metal ion. It should be noted that a combination of these two pathways could also occur with the same end result, i.e. the monomeric form of (Ar)DPPMn. 


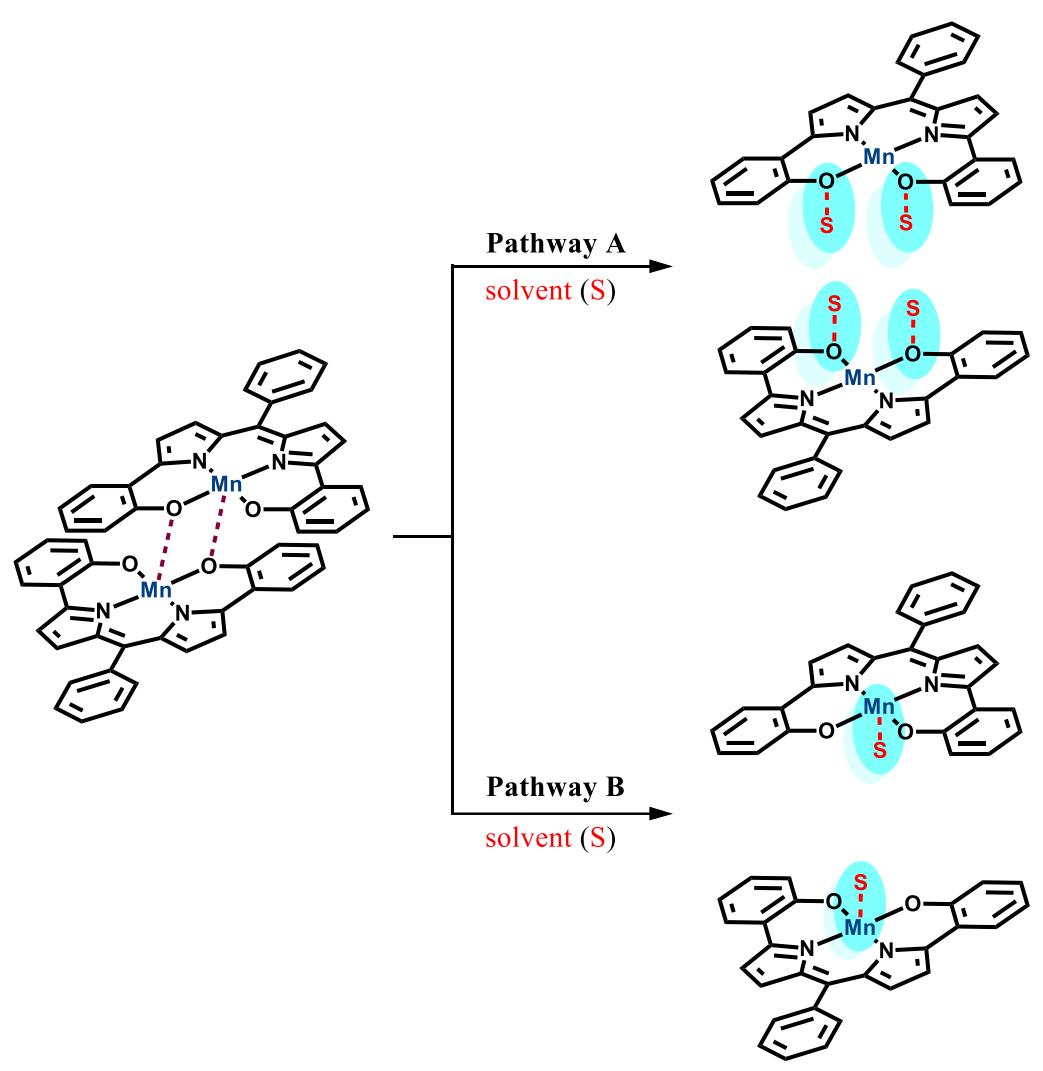

Scheme 1. Possible products of dimer dissociation.

One way to differentiate between Pathway A and B of Scheme 1 would be to add a reagent which could interact with the phenolic oxygen atoms of the (Ar)DPP ligand but not bind axially and this suggested to us the possibility of breaking the dimer under noncoordinating solution conditions (i.e. $\mathrm{CH}_{2} \mathrm{Cl}_{2}$ and $\mathrm{C}_{2} \mathrm{H}_{4} \mathrm{Cl}_{2}$ containing $0.1 \mathrm{M} \mathrm{TBAPF}_{6}$ ) and added protons in the form of TFA. This is indeed what is observed as shown in Figure 12, where well-defined, reversible reductions $\left(\Delta E_{\mathrm{p}}=80 \mathrm{mV}\right)$ are seen after the addition of 2 equivalents of protons to solution. At the same time, no changes are seen in the oxidation behavior, indicating that the manganese metal ion is still present in the molecule and that no demetallation has occurred upon the addition of acid.

It should also be noted that an electrochemically detectable dimerization during reduction but not upon oxidation can be rationalized by the different sites of electron transfer; i.e. an electron is added to the manganese center during reduction while electron abstraction takes place on the (Ar)DPP ring during oxidation. It should also be noted that ring centered redox processes are typically rapid (reversible) electron 
transfers while $\mathrm{Mn}^{\mathrm{III}}$-centered reductions would be slower as is often observed for $\mathrm{Mn}^{\mathrm{III}}$ reductions at the metal center. ${ }^{16-18,38-43}$

(a) (Ph)DPPMn

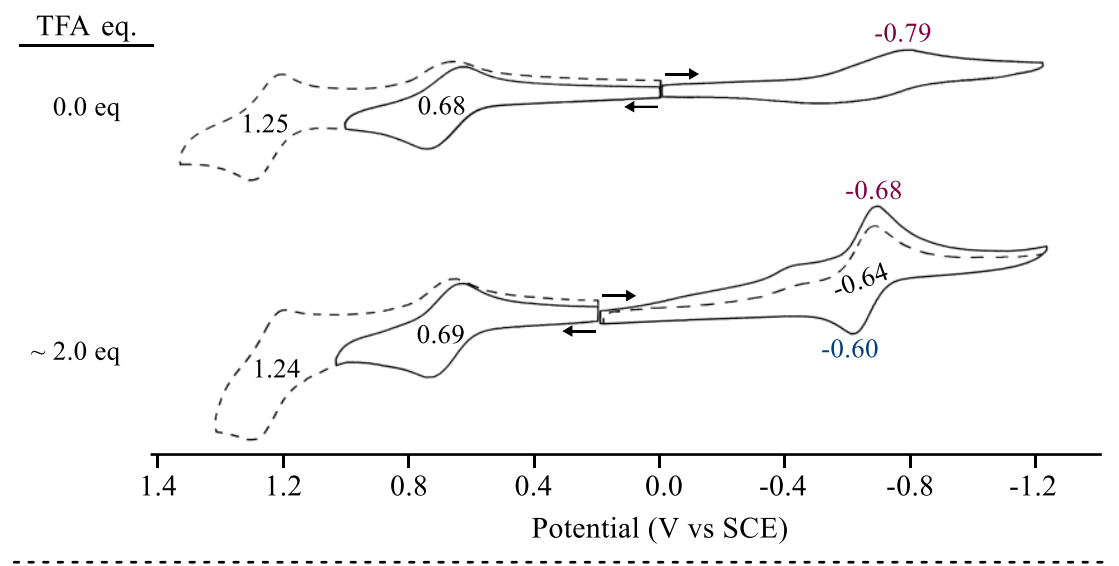

(b) (Mes)DPPMn

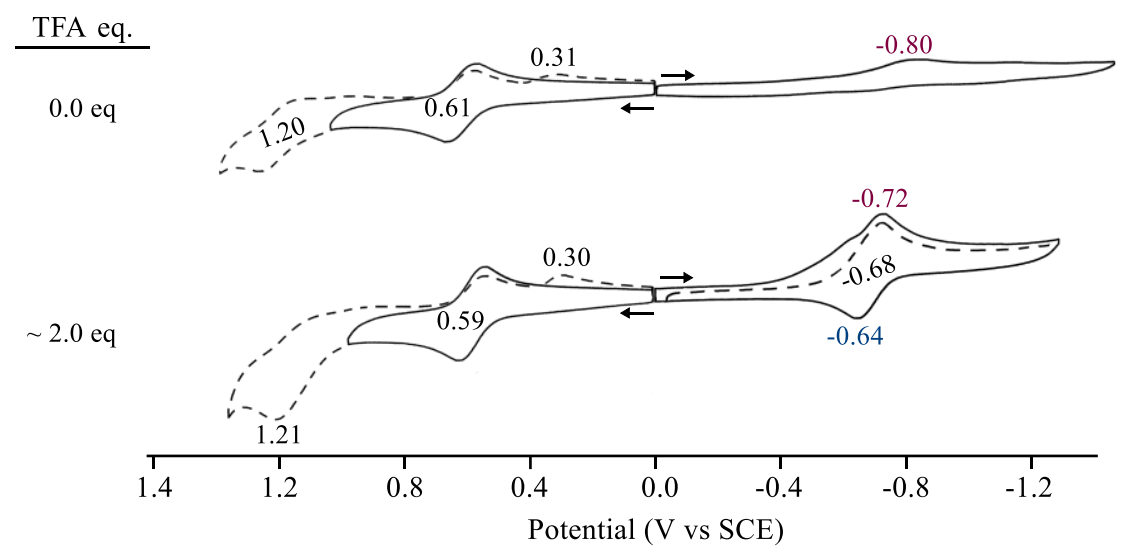

Figure 12. Cyclic voltammograms of (a) (Ph)DPPMn and (b) (Mes)DPPMn at $10^{-3} \mathrm{M}$ in $\mathrm{CH}_{2} \mathrm{Cl}_{2}$ containing $0.1 \mathrm{M} \mathrm{TBAPF} 6$ before and after the addition of 2.0 eq TFA. A second cathodic scan showing the disappearance of the adsorption peak is given by the dotted line from $\sim 0.0$ to $-1.2 \mathrm{~V}$.

Effect of Anions on Electrochemical Behavior and Spectra. The effect of anions on the metalcentered reduction of (Ar)DPPMn was investigated in $\mathrm{CH}_{2} \mathrm{Cl}_{2}$ containing seven different $\mathrm{TBA}^{+} \mathrm{X}^{-}$salts. Examples of cyclic voltammograms are given in Figure 13 and the measured potentials are summarized in Table 4. Again, larger than theoretical values of $\Delta E_{\mathrm{p}}$, ranging from 0.36 to $0.51 \mathrm{~V}$, are seen for the (slow) metal-centered reduction in $\mathrm{CH}_{2} \mathrm{Cl}_{2}$ containing $\mathrm{F}^{-}, \mathrm{OH}^{-}, \mathrm{Cl}^{-}$or $\mathrm{CN}^{-}$while broad reduction peaks with decreased currents are seen in $\mathrm{CH}_{2} \mathrm{Cl}_{2}$ solutions containing $\mathrm{ClO}_{4}^{-}$or $\mathrm{PF}_{6}^{-}$, this result being consistent with dimerization under these noncoordinating solution conditions. At the same time, the ring-centered 
oxidations under the same solution condition are more reversible $\left(\Delta E_{\mathrm{p}}=0.10\right.$ to $\left.0.17 \mathrm{~V}\right)$. Thus, the more basic, complexing anions act to break up the dimer, leading to well-defined but still slow (quasireversible) electroreductions as seen in Figure 13 for (Ph)DPPMn in solutions containing $0.1 \mathrm{M} \mathrm{TBACl}$ and TBAOH.

Table 4. Halfwave potentials ( $\mathrm{V} v s \mathrm{SCE}$ ) and anodic to cathodic peak separations $\left(\Delta E_{\mathrm{p}}\right)$ for reduction and oxidation of (Ph)DPPMn in $\mathrm{CH}_{2} \mathrm{Cl}_{2}$ with $0.1 \mathrm{M}$ supporting electrolyte, TBAX (X = $\mathrm{PF}_{6}^{-}, \mathrm{ClO}_{4}^{-}, \mathrm{BF}_{4}^{-}, \mathrm{Cl}^{-}$, $\mathrm{F}^{-}, \mathrm{OH}^{-}$or $\left.\mathrm{CN}^{-}\right)$.

\begin{tabular}{llllll}
\hline \multirow{2}{*}{$\mathrm{X}^{-}$} & \multicolumn{2}{c}{ Ligand Oxidation } & & $\left(\mathrm{Mn}^{\mathrm{III}} / \mathrm{Mn}^{\mathrm{II}}\right)$ & Ligand Reduction \\
\cline { 2 - 3 } & $2^{\text {nd }}\left(\Delta E_{\mathrm{p}}\right)$ & $1^{\mathrm{st}}\left(\Delta E_{\mathrm{p}}\right)$ & & $E_{1 / 2}\left(\Delta E_{\mathrm{p}}\right)$ & \multicolumn{1}{c}{$1^{\text {st }}$} \\
\cline { 1 - 3 } \cline { 5 - 6 } $\mathrm{PF}_{6}^{-}$ & $1.25(0.10)$ & $0.68(0.10)$ & & $-0.79^{\mathrm{a}}$ & $\mathrm{b}$ \\
$\mathrm{ClO}_{4}^{-}$ & $1.16(0.10)$ & $0.68(0.10)$ & & $-0.78^{\mathrm{a}}$ & $\mathrm{b}$ \\
$\mathrm{BF}_{4}^{-}$ & $1.27(0.10)$ & $0.78(0.12)$ & & $-0.83^{\mathrm{a}}$ & $\mathrm{b}$ \\
$\mathrm{F}^{-}$ & $\mathrm{b}$ & $\mathrm{b}$ & & $-0.55(0.51)$ & $-1.68^{\mathrm{a}}$ \\
$\mathrm{OH}^{-}$ & $\mathrm{b}$ & $\mathrm{b}$ & & $-0.70(0.52)$ & $-1.64^{\mathrm{a}}$ \\
$\mathrm{Cl}^{-}$ & $\mathrm{b}$ & $0.65(0.17)$ & $-0.67(0.38)$ & $\mathrm{b}$ \\
$\mathrm{CN}^{-}$ & $\mathrm{b}$ & $\mathrm{b}$ & $-0.62(0.36)$ & $-1.77^{\mathrm{a}}$ \\
\hline
\end{tabular}

${ }^{\mathrm{a}}$ Irreversible peak potential at scan rate of $0.1 \mathrm{~V} / \mathrm{s} .{ }^{\mathrm{b}}$ Reaction not observed due to limited solvent potential window.

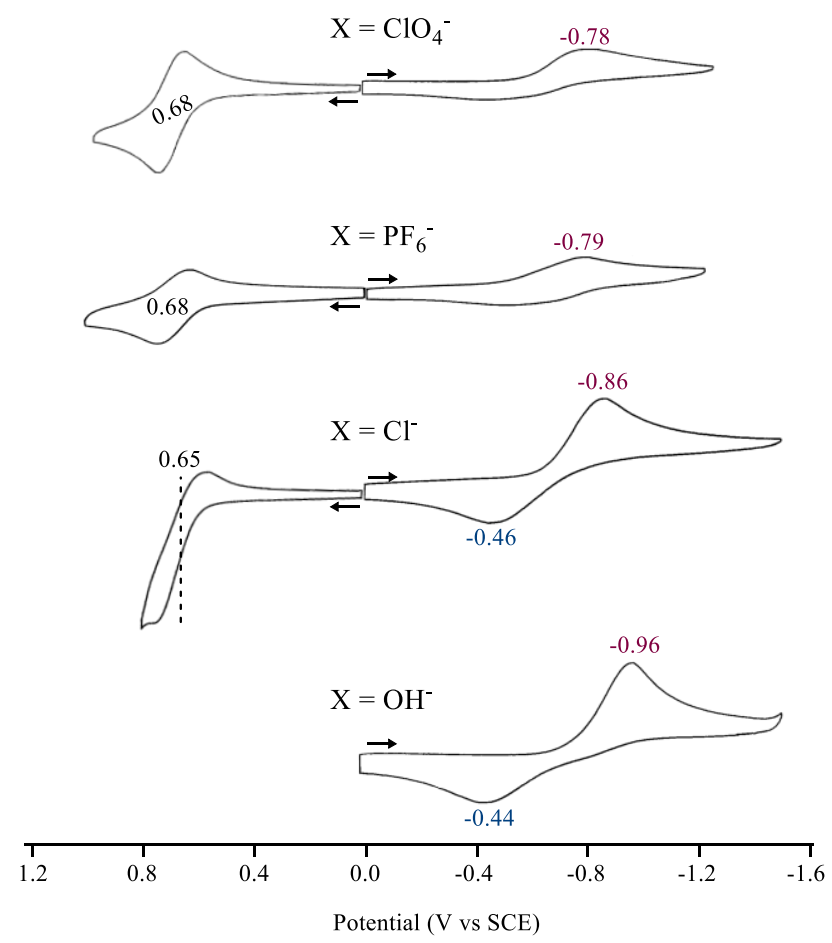

Figure 13. Cyclic voltammograms of (Ph)DPPMn at $10^{-3} \mathrm{M}$ comparing the first reduction and first oxidation in $\mathrm{CH}_{2} \mathrm{Cl}_{2}$ containing $0.1 \mathrm{M}$ TBAX, where $\mathrm{X}=\mathrm{PF}_{6}^{-}, \mathrm{X}=\mathrm{ClO}_{4}^{-}, \mathrm{X}=\mathrm{Cl}^{-}$and $\mathrm{X}=\mathrm{OH}^{-}$. Scan rate $=0.1 \mathrm{~V} / \mathrm{s}$. 
There is no obvious trend in the halfwave potentials for reduction with changes of anion (Table 4) and there are also no obvious trends in the position of the visible band for the neutral or singly reduced species in the presence of the different anions (Table 5 and Figure 14 for ( $\mathrm{Ph}$ )DPPMn in $\mathrm{CH}_{2} \mathrm{Cl}_{2} / 0.1 \mathrm{M}$ TBAX). The overall changes in the spectral patterns are similar to what is seen upon changing the solvent, as discussed earlier in the manuscript. Moreover, it should be noted that despite the fact that all of the reductions in Figure 14 involve a $\mathrm{Mn}^{\mathrm{III} / \mathrm{II}}$ reaction, a smaller $36-45 \mathrm{~nm}$ blue shift of the major visible absorption band is seen upon reduction in the presence of $\mathrm{F}^{-}, \mathrm{Cl}^{-}, \mathrm{CN}^{-}$or $\mathrm{OH}^{-}$anions as compared to the 50$68 \mathrm{~nm}$ blue shift which occurs with change of solvent (Figure 7).

Table 5. UV-vis spectral data of $(\mathrm{Ph}) \mathrm{DPPMn}{ }^{\mathrm{n}}\left(\mathrm{n}=\mathrm{III}\right.$ or II) at $\sim 10^{-4} \mathrm{M}^{\text {in }} \mathrm{CH}_{2} \mathrm{Cl}_{2}$ containing $0.1 \mathrm{M}$ TBAX $\left(\mathrm{X}=\mathrm{PF}_{6}^{-}, \mathrm{BF}_{4}^{-}, \mathrm{ClO}_{4}^{-}, \mathrm{F}^{-}, \mathrm{OH}^{-}, \mathrm{Cl}^{-}\right.$or $\left.\mathrm{CN}^{-}\right)$.

\begin{tabular}{|c|c|c|c|c|c|c|}
\hline \multirow{2}{*}{$\begin{array}{l}\text { Ox. State } \\
\mathrm{Mn}^{\mathrm{III}}\end{array}$} & \multirow{2}{*}{$\frac{\mathrm{X}^{-}}{\mathrm{PF}_{6}^{-}}$} & \multicolumn{5}{|c|}{$\lambda, \mathrm{nm}\left(\varepsilon \times 10^{-4}, \mathrm{M}^{-1} \cdot \mathrm{cm}^{-1}\right)^{\mathrm{a}}$} \\
\hline & & $320(0.47)$ & & $459(0.20)$ & $617(0.24)$ & $669(0.36)$ \\
\hline & $\mathrm{BF}_{4}^{-}$ & $320(0.76)$ & & $459(0.24)$ & $619(0.23)$ & $670(0.39)$ \\
\hline & $\mathrm{ClO}_{4}^{-}$ & $323(0.49)$ & $419(0.23)$ & $460(0.24)$ & $621(0.26)$ & $673(0.47)$ \\
\hline & $\mathrm{F}^{-}$ & $321(2.38)$ & $421(0.60)$ & $458(0.46)$ & $605(0.85)$ & $656(2.09)$ \\
\hline & $\mathrm{OH}^{-}$ & $320(2.90)$ & $421(0.78)$ & $472(0.38)$ & $605(1.08)$ & $656(2.76)$ \\
\hline & $\mathrm{Cl}^{-}$ & $320(2.93)$ & $421(0.75)$ & $472(0.75)$ & $615(1.11)$ & $666(2.31)$ \\
\hline & $\mathrm{CN}^{-}$ & $320(2.43)$ & $429(0.67)$ & $464(0.54)$ & $619(0.78)$ & $670(1.86)$ \\
\hline \multirow[t]{7}{*}{$\mathrm{Mn}^{\mathrm{II}}$} & $\mathrm{PF}_{6}^{-}$ & $312(0.51)$ & & $429(0.10)$ & $561(0.30)$ & $606(0.51)$ \\
\hline & $\mathrm{BF}_{4}^{-}$ & $315(0.59)$ & & $437(0.17)$ & $572(0.40)$ & $613(0.61)$ \\
\hline & $\mathrm{ClO}_{4}^{-}$ & $314(0.55)$ & & $444(0.17)$ & $569(0.38)$ & $616(0.62)$ \\
\hline & $\mathrm{F}^{-}$ & $314(1.59)$ & & $442(0.51)$ & $575(1.23)$ & $620(2.13)$ \\
\hline & $\mathrm{OH}^{-}$ & $315(2.29)$ & & $443(0.60)$ & $567(1.67)$ & $609(3.21)$ \\
\hline & $\mathrm{Cl}^{-}$ & $310(1.72)$ & & $450(0.42)$ & $569(0.82)$ & $630(2.80)$ \\
\hline & $\mathrm{CN}^{-}$ & $313(1.84)$ & & $454(0.58)$ & $583(1.72)$ & $624(2.17)$ \\
\hline
\end{tabular}

${ }^{\mathrm{a}} \varepsilon$ values were calculated based on the monomeric compound. 
(a) $\mathrm{F}^{-}$

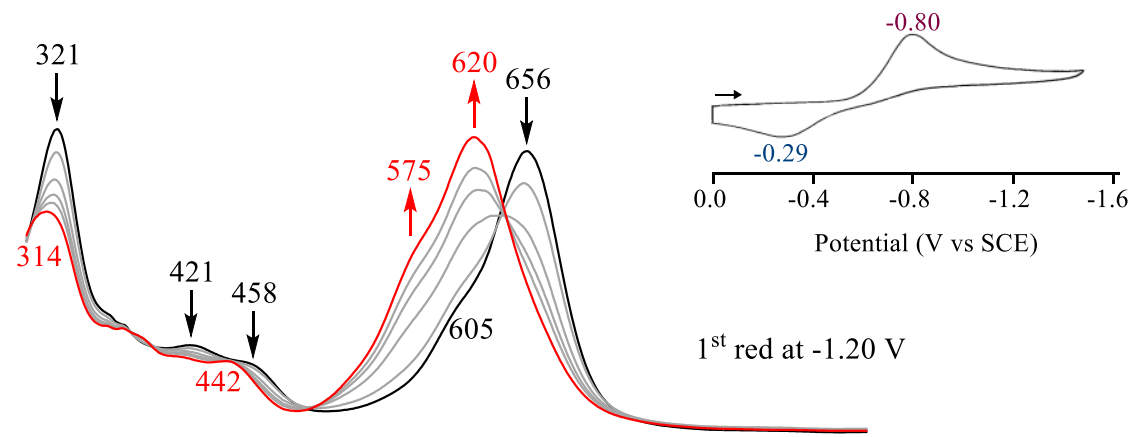

(b) $\mathbf{O H}^{-}$
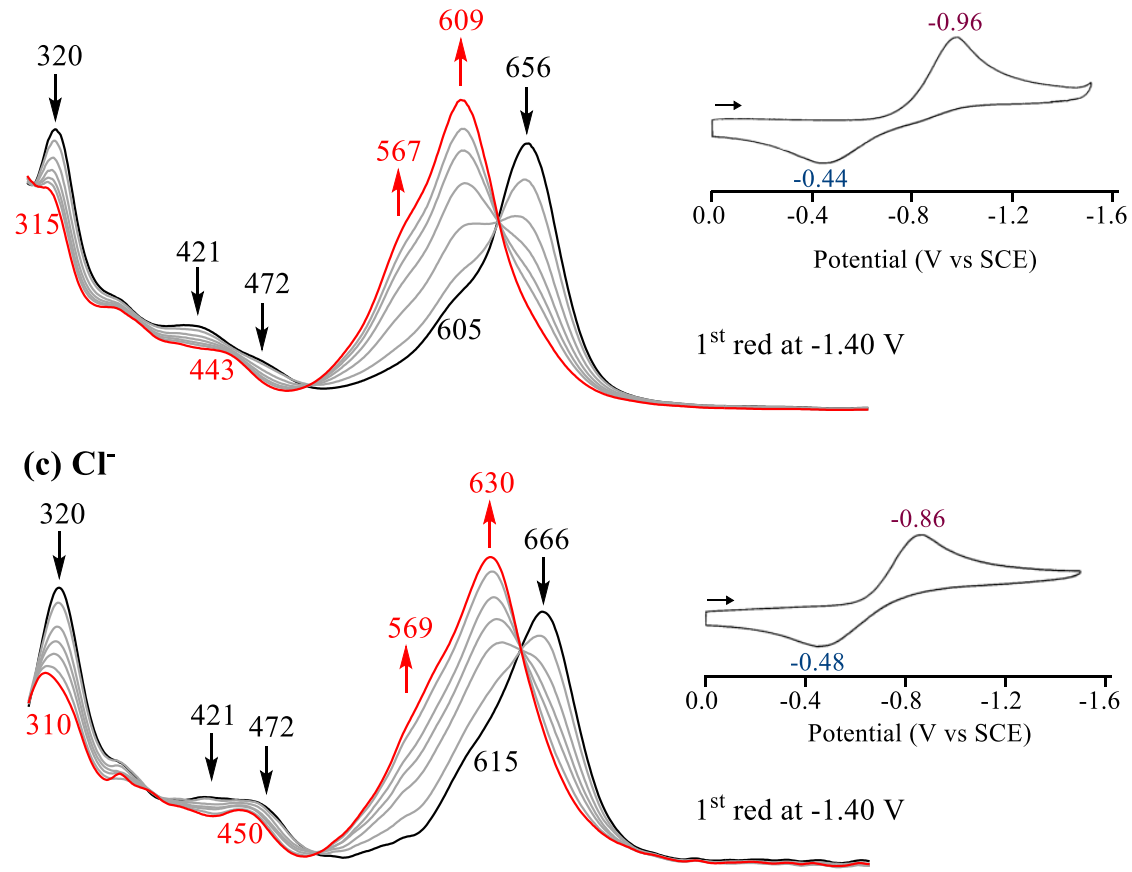

(d) $\mathrm{CN}^{-}$

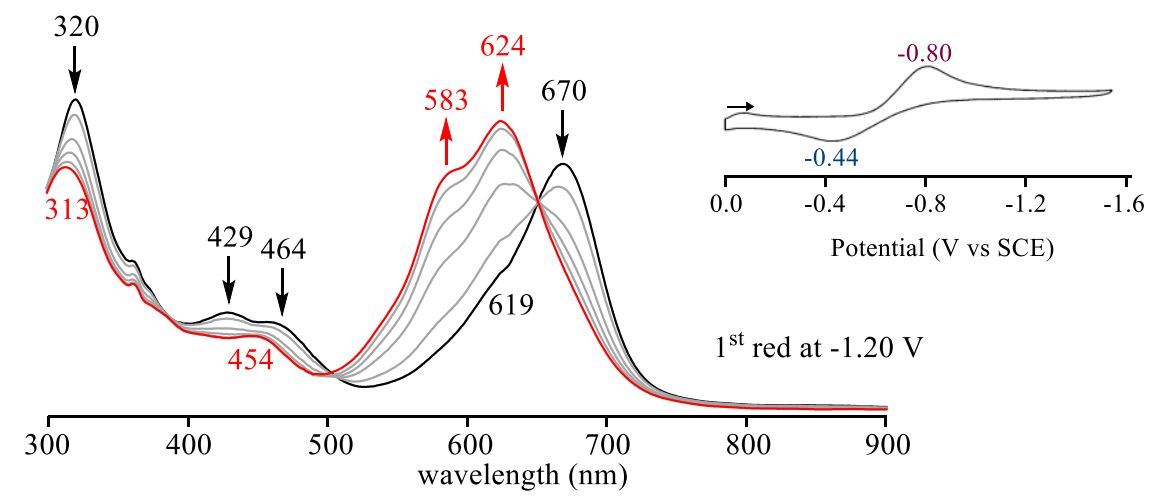

Figure 14. UV-vis spectral changes during the first reduction of (Ph)DPPMn in $\mathrm{CH}_{2} \mathrm{Cl}_{2}$ containing $0.1 \mathrm{M}$ TBAX where $\mathrm{X}$ is (a) $\mathrm{F}^{-}$, (b) $\mathrm{OH}^{-}$, (c) $\mathrm{Cl}^{-}$and (d) $\mathrm{CN}^{-}$. 
Again, the molar absorptivities (ع) increase significantly upon changing from $\mathrm{X}=\mathrm{PF}_{6}^{-}$or $\mathrm{ClO}_{4}^{-}$to $\mathrm{X}=\mathrm{F}^{-}, \mathrm{OH}^{-}, \mathrm{Cl}^{-}$or $\mathrm{CN}^{-}$as seen in Table 5 and Figure 15 which plots selected $\mathrm{UV}$-visible spectra under the different solution conditions. The marked increase of $\varepsilon$ upon going from solutions containing noncoordinating anions to strongly coordinating anions provides further evidence for the existence of homodimers in solution which are dissociated in the presence of anions such as $\mathrm{OH}^{-}$and $\mathrm{F}^{-}$.

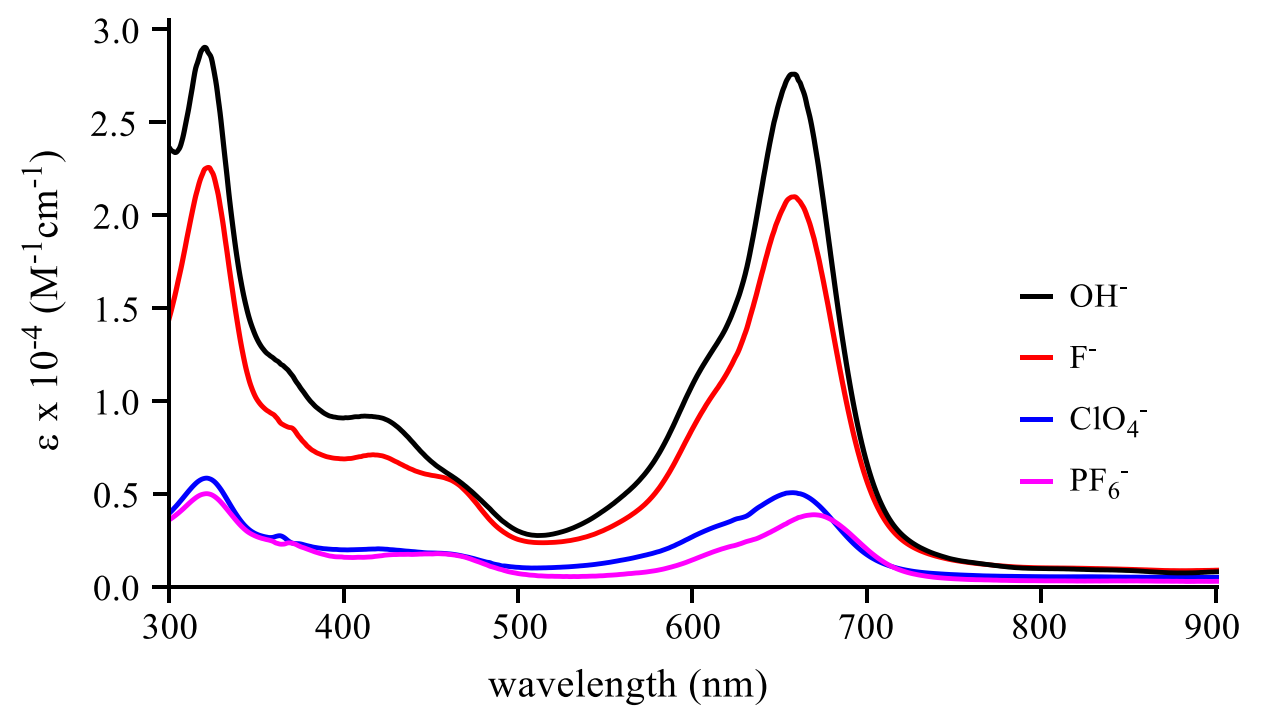

Figure 15. Normalized UV-vis spectra of neutral ( $\mathrm{Ph}$ )DPPMn ${ }^{\mathrm{III}}$ in $\mathrm{CH}_{2} \mathrm{Cl}_{2}$ containing $\mathrm{OH}^{-}$(black line), $\mathrm{F}^{-}$ (red line), $\mathrm{ClO}_{4}^{-}$(blue line) and $\mathrm{PF}_{6}^{-}$(pink line).

Drawing Comparisons between the different macrocycles. Halfwave potentials for reversible reductions and oxidations of the manganese(III) macrocycles in Chart 1 are compared in Scheme 2 where the listed $E_{1 / 2}$ values for $(\mathrm{Ph})_{3} \mathrm{CorMn},{ }^{35}(\mathrm{Ph}) \mathrm{DPPMn}$ and $(\mathrm{Ph})_{4} \mathrm{PorMnCl}^{49}$ were measured in $\mathrm{CH}_{3} \mathrm{CN}, 0.1 \mathrm{M}$ $\mathrm{TBAClO}_{4}$ while potentials for $(\mathrm{TBP})_{8} \mathrm{CzMn}$ were obtained in $\mathrm{PhCN}, 0.1 \mathrm{M} \mathrm{TBAClO}{ }_{4}(\mathrm{TBP}=p$-tertbutylphenyl). ${ }^{32}$ 
Scheme 2. Comparison of electrochemical potentials for the different manganese(III) macrocycles in Chart 1.

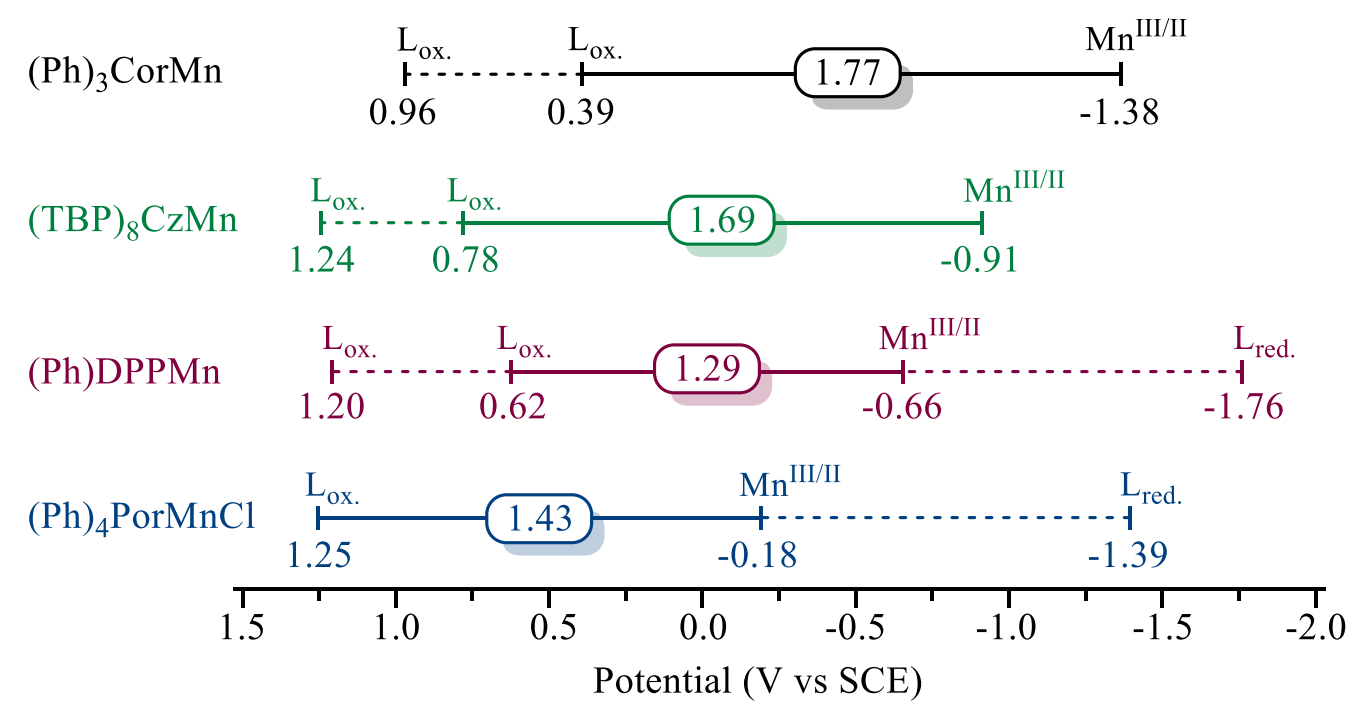

The first one-electron reduction was in each case assigned as an $\mathrm{Mn}^{\mathrm{IIIIII}}$ process while the first oxidation of $(\mathrm{TBP})_{8} \mathrm{CzMn}$ and $(\mathrm{Ph})_{4} \mathrm{PorMnCl}$ were assigned as ligand-centered, ${ }^{30,32}$ as also occurs for (Ph)DPPMn (see earlier discussion). A number of earlier studies assigned the first one-electron oxidation of $\mathrm{Mn}^{\mathrm{III}}$ corroles as metal-centered ${ }^{18,35,36,50}$ but Ghosh's more recent characterization of $(\mathrm{Ph})_{3} \mathrm{CorMnCl}$ as a noninnocent $\mathrm{Mn}^{\mathrm{III}}$-corrole cation radical $^{21,} 25$ would suggest that conversion of $(\mathrm{Ph})_{3} \mathrm{CorMn}$ to $\left[(\mathrm{Ph})_{3} \mathrm{CorMn}\right]^{+}$can also be assigned as a ligand-centered electron abstraction. This is the assignment given in Scheme 2 where the first reversible one-electron reduction of all four manganese(III) macrocycles involves the metal center and the first reversible one-electron oxidation involves the conjugate macrocycle, where the potential is indicated by $\mathrm{L}_{\mathrm{ox}}$.

It was recently shown that four- and five-coordinate (Ar)DPPCo complexes, which contained noninnocent DPP ligands, had redox behavior which resembled that of noninnocent four- and fivecoordinate corroles, $(\mathrm{Ar})_{3}$ CorCo, both undergoing a facile one-electron reductions. ${ }^{20}$ For example, the oneelectron reduction of $(\mathrm{Ph}) \mathrm{DPPCo}$ and $(\mathrm{Ph})_{3} \mathrm{CorCo}$ occurs at 0.08 and $-0.19 \mathrm{~V}$ in $\mathrm{CH}_{2} \mathrm{Cl}_{2}, 0.1 \mathrm{M} \mathrm{TBAClO} 4$ and at -0.13 and $-0.39 \mathrm{~V}$ in DMSO, 0.1 $\mathrm{M} \mathrm{TBAClO}_{4}$, respectively. The easier 260-270 $\mathrm{mV}$ shift in $E_{1 / 2}$ for reduction of the $(\mathrm{Ph}) \mathrm{DPPCo}$ as compared to the related triphenylcorrole is not associated with similar shifts 
in potential for oxidation where the difference in $E_{1 / 2}$ between corrole and DPP is negligible. A much larger difference in potentials is seen for the DPP and corrole derivatives of $\mathrm{Mn}^{\mathrm{III}}$ and $\mathrm{Au}^{\mathrm{III}}$, both of which contain innocent macrocycles. In this case, the DPP derivatives are both easier to reduce and harder to oxidize than the related corroles, as shown by the data values in Table 6 .

Table 6. Comparison of first reduction and first oxidation potentials (V vs SCE) of metallo DPP and Cor complexes containing only meso-phenyl rings unless otherwise noted.

\begin{tabular}{|c|c|c|c|c|c|c|c|}
\hline \multirow[b]{2}{*}{ Solvent } & \multirow[b]{2}{*}{ Metal } & \multicolumn{3}{|c|}{$1^{\text {st }}$ Red. } & \multicolumn{3}{|c|}{$1^{\text {st }} \mathrm{Ox}$} \\
\hline & & (Ar)DPP & (Ar)Cor & $\Delta E_{\text {Red }}$ & (Ar)DPP & (Ar)Cor & $\Delta E_{0 x}$ \\
\hline $\mathrm{CH}_{3} \mathrm{CN}$ & $\mathrm{Mn}$ & -0.66 & $-1.38^{\mathrm{a}}$ & 0.72 & 0.61 & $0.39^{\mathrm{a}}$ & 0.22 \\
\hline $\mathrm{PhCN}$ & $\mathrm{Au}$ & $-0.89^{\mathrm{b}}$ & $-1.40^{\mathrm{c}}$ & 0.51 & $0.96^{\mathrm{b}}$ & $0.80^{c}$ & 0.16 \\
\hline $\mathrm{CH}_{2} \mathrm{Cl}_{2}$ & Co & $0.08^{\mathrm{d}}$ & $-0.19^{\mathrm{e}}$ & 0.27 & $0.57^{\mathrm{d}}$ & $0.54^{\mathrm{e}}$ & 0.03 \\
\hline DMSO & Co & $-0.13^{\mathrm{d}}$ & $-0.39^{\mathrm{e}}$ & 0.26 & $0.44^{\mathrm{d}}$ & $0.39^{\mathrm{e}}$ & 0.05 \\
\hline
\end{tabular}

${ }^{a}$ Taken from ref. 35. ${ }^{\mathrm{b}}$ Taken from ref. 22. ${ }^{\mathrm{c}}$ Taken from ref. 51. ${ }^{\mathrm{d}}$ Taken from ref. 20. ${ }^{\mathrm{e}}(\mathrm{Mes}){ }_{3}$ CorCo from ref. 52.

The first one-electron reduction and first one-electron oxidation of $(\mathrm{TBP})_{8} \mathrm{CzMn}$ are located at -0.91 and $-0.78 \mathrm{~V}$ in PhCN, $0.1 \mathrm{M} \mathrm{TBAClO}_{4}$ and the measured electrochemical HOMO-LUMO gap $\left(\Delta E_{\mathrm{H}-\mathrm{L}}\right)$ of $1.69 \mathrm{~V}$ is quite similar to the $1.77 \mathrm{~V}$ gap for $(\mathrm{Ph})_{3} \mathrm{CorMn}$, both values being larger than what is measured for $(\mathrm{Ph}) \mathrm{DPPMn}\left(\Delta E_{\mathrm{H}-\mathrm{L}}=1.29 \mathrm{~V}\right)$ and $(\mathrm{Ph})_{4} \mathrm{PorMnCl}\left(\Delta E_{\mathrm{H}-\mathrm{L}}=1.43 \mathrm{~V}\right)$ as seen in Scheme 2. This would suggest a difference between the innocent manganese macrocycles $(\mathrm{Ph})_{3} \mathrm{CorMn}$ and $(\mathrm{Ph}) \mathrm{DPPMn}$, but it should also be noted that the $\Delta \mathrm{E}_{1 / 2}$ between the first and second oxidations of these two compounds are essentially identical, these separation being 570 and $580 \mathrm{mV}$, respectively. The similar separations further suggest that both oxidations of $(\mathrm{Ph})_{3} \operatorname{CorMn}\left(E_{1 / 2}=0.39\right.$ and $\left.0.96 \mathrm{~V}\right)$ and $(\mathrm{Ph}) \mathrm{DPPMn}\left(E_{1 / 2}=0.62\right.$ and 1.20 V) are ligand-centered electron abstractions. Finally, it should be noted that the potential difference between $E_{1 / 2}$ for the $\mathrm{Mn}^{\mathrm{III} / \mathrm{II}}$ process and the first ligand-centered reduction of $(\mathrm{Ph}) \mathrm{DPPMn}(1.10 \mathrm{~V})(\mathrm{Ph})_{4} \mathrm{PorMnCl}$ $(1.20 \mathrm{~V})$ are quite similar to each other, and the sufficiently large separation rules out a two ligand-centered reduction processes.

The relative ease of the $\mathrm{Mn}^{\mathrm{III} / \mathrm{II}}$ reduction potential for the macrocycles in Scheme 2 follows the order $(\mathrm{Ph})_{4} \mathrm{PorMnCl}(-0.18 \mathrm{~V})>(\mathrm{Ph}) \mathrm{DPPMn}(-0.66 \mathrm{~V})>(\mathrm{Ph})_{3}$ CorMn $(-1.38 \mathrm{~V})$ and is reproduced by the computationally determined LUMO energies as seen in Figure 16. The theoretical LUMO's of each macrocycle are delocalized but include orbitals of the manganese central metal ion, in line with the observed metal-centered reduction. This delocalization of the LUMO orbitals over the ligand and metal center is 
consistent with the earlier proposed intramolecular electron transfer (IMET) during the first reduction of the manganese(III) DPP, i.e. a process where the electron addition first occurs at the DPP ligand $\pi$ orbitals and is subsequently transferred to the manganese(III) center ultimately giving [(Ar)DPPMn $\left.{ }^{\mathrm{II}}\right]^{-}$as a final product (see Figure 4 and related discussion). In contrast, a much smaller metal character is observed for the theoretical HOMO orbitals, thus supporting a ligand-centered oxidation process in each case (see also spin density of $\left[(\mathrm{Ph}) \mathrm{DPP}^{\bullet} \mathrm{Mn}\right]^{+}$in Figure S2). Moreover, the shift in experimentally measured oxidation potentials for the three manganese(III) complexes $(0.39,0.62$ and $1.25 \mathrm{~V}$ in Scheme 2$)$ is also reproduced by the DFT calculations, which predict the trend in $\mathrm{HOMO}$ energies to be $(\mathrm{Ph})_{3} \mathrm{CorMn}>(\mathrm{Ph}) \mathrm{DPPMn}>$ $(\mathrm{Ph})_{4} \mathrm{PorMnCl}$, as depicted in Figure 16. It should also be noted that a strong correlation exists between the computationally determined HOMO/LUMO energies and the experimentally measured potentials listed in Scheme 2, resulting nearly uniform correlation coefficients $\left(\mathrm{R}^{2}=0.999\right)$ as seen in Figures S5 and S6.

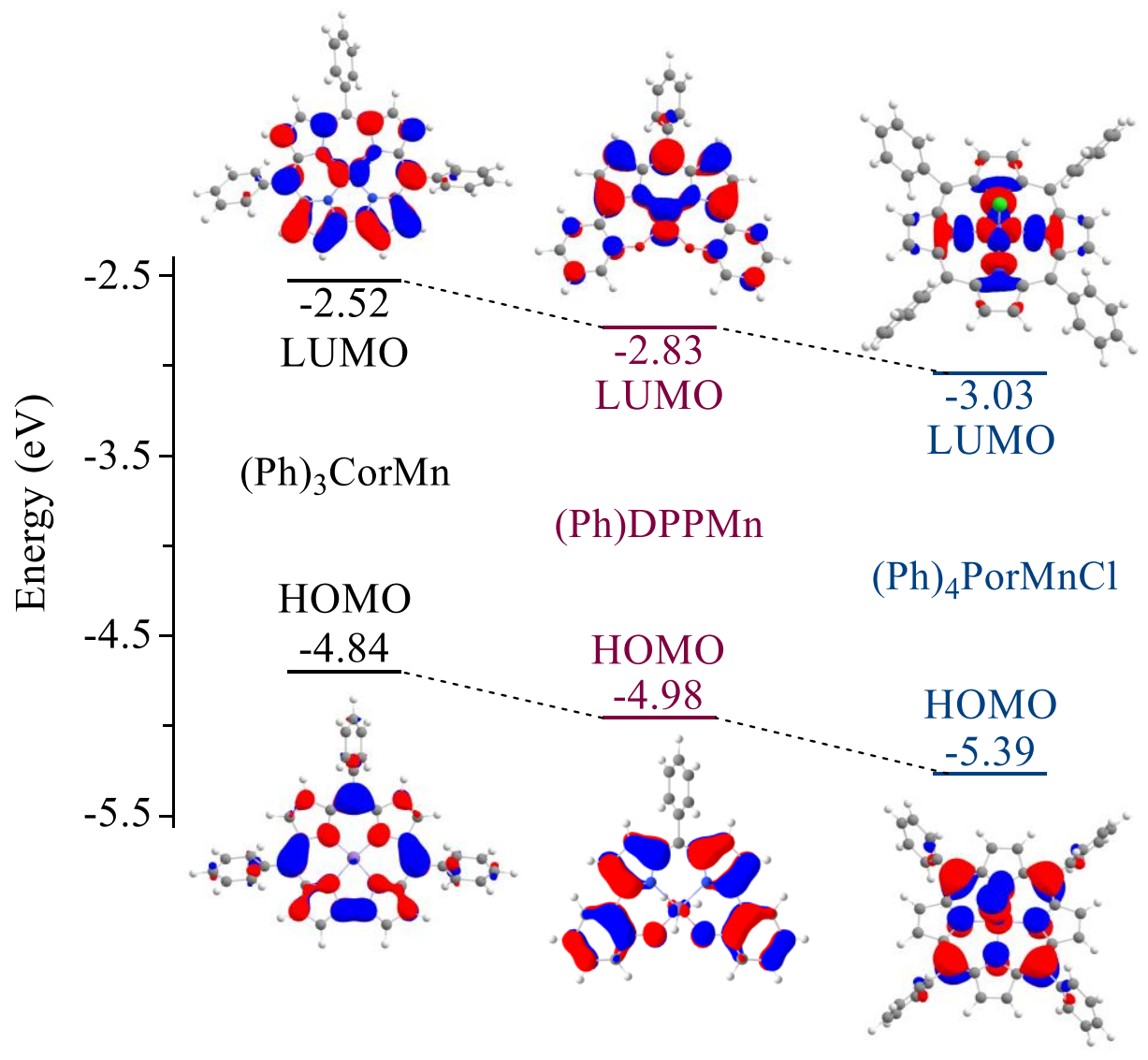

Figure 16. HOMO-LUMO Orbitals and the corresponding energies (in eV) for the manganese(III) macrocycles $(\mathrm{Ph})_{3} \mathrm{CorMn}^{\mathrm{III}},(\mathrm{Ph}) \mathrm{DPPMn}^{\mathrm{III}}$ and $(\mathrm{Ph})_{4} \mathrm{TPPMn}^{\mathrm{III}} \mathrm{Cl}$. 
Finally there remains the question of how manganese(III) dipyrrin-bisphenols fit the emerging analogy between DPP and corroles described earlier for cobalt derivatives of the two macrocycles. While the innocence of the two trivalent macrocycles is maintained for both manganese DPP and manganese corrole complexes, no evident parallels can be seen in the electrochemical potentials or sites of electrontransfer for oxidation. In particular, the first reduction of (Ar)DPPMn is metal-centered and occurs at a substantially more positive potential (easier reduction) when compared to the $\mathrm{Mn}^{\mathrm{III} / \mathrm{II}}$ reaction of the structurally related corrole under the same electrochemical conditions (see Scheme 2). Moreover, the first oxidation of (Ar)DPPMn is clearly ligand-centered as opposed to a metal-centered $\mathrm{Mn}^{\mathrm{III} / \mathrm{V}}$ process observed for the first oxidation of $(\mathrm{Ar})_{3} \mathrm{CorMn}$. Given these results, and the existing electrochemical data regarding DPP and corrole complexes with different metal ions, it appears that only noninnocent assemblies (i.e. where $\mathrm{M}=\mathrm{Cu}$ or $\mathrm{Co}$ ) adhere to the electrochemical analogy between DPP and corrole macrocycles. However, this conclusion is not yet definitive and is currently under further investigation for other substituted DPP derivatives containing various metal ions.

\section{EXPERIMENTAL SECTION}

Instrumentation and Methods. ${ }^{1} \mathrm{H}$ NMR spectra were recorded on a Bruker Avance Neo III 500 spectrometer operating at $500 \mathrm{MHz}$ and available at the PACSMUB-WPCM technological platform, which relies on the "Institut de Chimie Moléculaire de l'Université de Bourgogne" and SATT SAYENS "TM", a Burgundy University private subsidiary. All NMR shift values are expressed in ppm. ${ }^{1} \mathrm{H}$ spectra were calibrated using the residual peak of chloroform at $7.26 \mathrm{ppm}$. UV-visible spectra were recorded on a Hewlett-Packard Model 8453 diode array or on a Varian Cary 50 spectrophotometer. Quartz cells with optical path lengths of $10 \mathrm{~mm}$ were used. ESI mass spectra were recorded on a LTQ Orbitrap XL (THERMO) instrument for HR-MS spectra and on an AmaZon SL (Bruker) instrument for the LRMS spectra.

Cyclic voltammetry $(\mathrm{CV})$ measurements were performed at $298 \mathrm{~K}$ on an EG\&G model 173 potentiostat coupled with an EG\&G model 175 universal programmer in nonaqueous solution containing 0.1 $\mathrm{M} \mathrm{TBAClO}_{4}$ as a supporting electrolyte. A three-electrode system composed of a glass carbon working 
electrode, a platinum wire counter electrode, and a saturated calomel reference electrode (SCE) was utilized. The reference electrode was separated from the bulk of the solution by a fritted-glass bridge filled with the solvent/supporting electrolyte mixture. Thin-layer spectroelectrochemical measurements were carried out using an optically transparent platinum thin-layer working electrode and a Hewlett-Packard model 8453 diode array spectrophotometer coupled with an EG\&G model 173 universal programmer.

Chemicals. Manganese Pentafluorophenyldipyrrin-bisphenol $\left(\left(\mathrm{F}_{5} \mathrm{Ph}\right) \mathrm{DPPMn}\right)$ was prepared as described in the literature. ${ }^{10}$ Dimethylsulfoxide (DMSO), Pyridine (Py), Tetrabutylammonium perchlorate $\left(\mathrm{TBAClO}_{4}\right), \quad$ Tetrabutylammonium hexafluorophosphate $\left(\mathrm{TBAPF}_{6}\right), \quad$ Tetrabutylammonium tetrafluoroborate $\left(\mathrm{TBABF}_{4}\right)$, Tetrabutylammonium fluoride (TBAF), Tetrabutylammonium chloride (TBACl), Tetrabutylammonium hydroxide (TBAOH), Tetrabutylammonium cyanide (TBACN) were purchased from Sigma Aldrich and $\mathrm{CH}_{2} \mathrm{Cl}_{2}$ was purchased from EMD Millipore Corporation. All chemicals were used without further purification. NMR solvents were purchased from Eurisotope and were used without further purification.

Computational details. Quantum mechanics calculations were performed with the Gaussian16 software package. ${ }^{53}$ Energy and forces were computed by density functional (DFT) theory with the hybrid B3LYP exchange-correlation functional, ${ }^{54-56}$ the def2-SVP basis set and pseudopotential for all atoms. ${ }^{57}$ Solvent effects were modelled by means of the continuum model within the SMD approach as implemented in Gaussian. ${ }^{58}$ Molecular orbitals and spin density images were generated with Chemcraft Version 1.8. ${ }^{59}$

General synthetic procedure for manganese dipyrrin-bisphenolate complexes. Manganese acetate (1.33 equiv) was added to a pink solution of the free dipyrrin-bisphenol ligand (31.3 mg) in a $1 / 1$ mixture of $\mathrm{EtOH} /$ toluene $(4.0 \mathrm{~mL})$ and $\mathrm{Et}_{3} \mathrm{~N}(22.6 \mu \mathrm{L})$. The resulting suspension was stirred at $85^{\circ} \mathrm{C}$ for 2.5 hours and monitored with TLC. After completion of the reaction, the solvents were evaporated and the resulting complexes were purified as described below. $\left(\mathrm{F}_{5} \mathrm{Ph}\right) \mathrm{DPPMn}{ }^{10}$ and the free-base dipyrrin-bisphenol $[(\mathrm{Ph}) \mathrm{DPP}] \mathrm{H}_{3}$ and $[(\mathrm{Mes}) \mathrm{DPP}] \mathrm{H}_{3}$ were synthesized as described in the literature. ${ }^{2}$

(Ph)DPPMn. The meso-Ph derivative was purified over a silica gel column chromatography using dichloromethane and a mixture of dichloromethane and methanol (99/1). Yield $27.5 \mathrm{mg}(60.3 \mu \mathrm{mol}, 78 \%)$. 
UV-vis $\left(\mathrm{CH}_{2} \mathrm{Cl}_{2}\right) \lambda_{\max }\left[\mathrm{nm}, \varepsilon \times 10^{3}\left(\mathrm{M}^{-1} \mathrm{~cm}^{-1}\right)\right]: 318$ (10.9), 453 (4.52), 664 (8.56). MS (ESI) m/z = 456.03 $[\mathrm{M}]^{+}, 456.07$ calcd for $\mathrm{C}_{27} \mathrm{H}_{17} \mathrm{MnN}_{2} \mathrm{O}_{2} ; \mathrm{m} / \mathrm{z}=479.05[\mathrm{M}+\mathrm{Na}]^{+}, 479.06$ calcd for $\mathrm{C}_{27} \mathrm{H}_{17} \mathrm{MnN}_{2} \mathrm{NaO}_{2} ; \mathrm{m} / \mathrm{z}=$ $912.26[2 \mathrm{M}]^{+}, 912.34$ calcd for $\mathrm{C}_{54} \mathrm{H}_{34} \mathrm{Mn}_{2} \mathrm{~N}_{4} \mathrm{O}_{4}$. HR-MS (ESI) $\mathrm{m} / \mathrm{z}=456.06661[\mathrm{M}]^{+}, 456.06650$ calcd for $\mathrm{C}_{27} \mathrm{H}_{17} \mathrm{MnN}_{2} \mathrm{O}_{2}$. (See Figure S7)

(Mes)DPPMn. The mesityl DPP complex was purified over a silica gel column chromatography using dichloromethane and a mixture of dichloromethane and methanol (99/1). Yield $16.2 \mathrm{mg}(32.5 \mu \mathrm{mol}, 79 \%)$. UV-vis $\left(\mathrm{CH}_{2} \mathrm{Cl}_{2}\right) \lambda_{\max }\left[\mathrm{nm}, \varepsilon \times 10^{3}\left(\mathrm{M}^{-1} \mathrm{~cm}^{-1}\right)\right]: 308$ (21.6), 354 (10.9), 456 (7.26), 649 (11.7). MS (ESI) m/z $=498.11[\mathrm{M}]^{+}, 498.11$ calcd for $\mathrm{C}_{30} \mathrm{H}_{23} \mathrm{MnN}_{2} \mathrm{O}_{2} ; \mathrm{m} / \mathrm{z}=521.14[\mathrm{M}+\mathrm{Na}]^{+}, 521.10$ calcd for $\mathrm{C}_{30} \mathrm{H}_{23} \mathrm{MnN}_{2} \mathrm{NaO}_{2} . \mathrm{m} / \mathrm{z}=997.31[2 \mathrm{M}+\mathrm{H}]^{+}, 997.23$ calcd for $\mathrm{C}_{60} \mathrm{H}_{47} \mathrm{Mn}_{2} \mathrm{~N}_{4} \mathrm{O}_{4}$. HR-MS (ESI) $\mathrm{m} / \mathrm{z}=$ $498.11447[\mathrm{M}]^{+}, 498.11345$ calcd for $\mathrm{C}_{30} \mathrm{H}_{23} \mathrm{MnN}_{2} \mathrm{O}_{2}$. (see Figure $\mathrm{S} 7$ )

\section{ACKNOWLEDGEMENTS}

We gratefully acknowledge support from the Robert A. Welch Foundation (KMK, Grant E-680), Natural Science Foundation of China (Grant No. 21501070), China Postdoctoral Science Foundation (Grant 2019M661735), the CNRS (UMR UB-CNRS 6302), the "Université Bourgogne Franche-Comté", and the “Conseil Régional de Bourgogne” through the Plan d'Actions Régional pour l'Innovation (PARI II CDEA) and the European Union through the PO FEDER-FSE Bourgogne 2014/2020. The authors wish also to warmly thank Mr. Quentin Bonnin for technical assistance and the "Plateforme d'Analyse Chimique et de Synthèse Moléculaire de l'Université de Bourgogne" (SATT SAYENS, PACSMUB, http://www.wpcm.fr) for access to spectroscopy instrumentation (NMR, IR, ESI LRMS and HR-MS). Calculations were performed using HPC resources from DNUM CCUB (Centre de Calcul de l'Université de Bourgogne).

\section{ASSOCIATED CONTENT}

\section{Supporting information}

Supplementary data associated with this article can be found, in the online version, at http://pub.acs.org/doi/XXXX

Plots of $E_{1 / 2}$ versus $\sigma$ for the three redox processes in $\mathrm{CH}_{3} \mathrm{CN}$ and wavenumber $\left(\mathrm{cm}^{-1}\right)$ signature absorption band of the neutral, singly reduced and singly oxidized ( $\mathrm{Ar}$ )DPPMn complexes in $\mathrm{CH}_{3} \mathrm{CN}, 0.1 \mathrm{M} \mathrm{TBAPF}$. 
UV-vis spectral changes associated with the first reduction of $\left(\mathrm{F}_{5} \mathrm{Ph}\right) \mathrm{DPPM}$ and $(\mathrm{Ph}) \mathrm{DPPM}$ (where $\mathrm{M}=$ Mn or Co) in pyridine containing 0.1 $\mathrm{M} \mathrm{TBAClO}_{4}$. LRMS and HRMS (ESI) spectra of (Ph)DPPMn and (Mes)DPPMn. Spin density plot of $\left[(\mathrm{Ph}) \mathrm{DPP}^{\bullet} \mathrm{Mn}^{\mathrm{III}}\right]^{+}$and correlations of the HOMO/LUMO energies with the first oxidation/reduction potentials in acetonitrile.

\section{AUTHOR INFORMATION}

\section{Corresponding Authors}

Claude P. Gros - ICMUB, UMR CNRS 6302, Université Bourgogne Franche-Comté, 21000 Dijon, France; orcid.org/0000-0002-6966-947X; Email: claude.gros@u-bourgogne.fr

Karl M. Kadish - Department of Chemistry, University of Houston, Houston, TX 77204-5003 USA; orcid.org/0000-0003-4586-6732; Email: kadish@uh.edu

\section{Authors}

Yuanyuan Fang - School of Chemistry and Chemical Engineering, Jiangsu University, Zhenjiang 212013, China \& Department of Chemistry, University of Houston, Houston, TX 77204-5003 USA, orcid.org/00000002-4562-0727

W. Ryan Osterloh - Department of Chemistry, University of Houston, Houston, TX 77204-5003 USA; orcid.org/0000-0001-9127-2519

Nicolas Desbois - ICMUB, UMR CNRS 6302, Université Bourgogne Franche-Comté, 21000 Dijon, France; orcid.org/0000-0002-1156-4608

Sandrine Pacquelet - ICMUB, UMR CNRS 6302, Université Bourgogne Franche-Comté, 21000 Dijon, France.

Paul Fleurat-Lessard - ICMUB, UMR CNRS 6302, Université Bourgogne Franche-Comté, 21000 Dijon, France ; orcid.org/0000-0003-3114-2522.

\section{Notes}

The authors declare no competing financial interest. 


\section{REFERENCES}

1. Deschamps, J.; Chang, Y.; Langlois, A.; Desbois, N.; Gros, C. P.; Harvey, P. D., The First Example of Cofacial Bis(dipyrrins). New J. Chem. 2016, 40, 5835-5845.

2. Ikeda, C.; Ueda, S.; Nabeshima, T., Aluminium Complexes of $\mathrm{N}_{2} \mathrm{O}_{2}$-type Dipyrrins: The First Hetero-Multinuclear Complexes of Metallo-Dipyrrins with High Fluorescence Quantum Yields. Chem. Commun. 2009, 2544-2546.

3. Sakamoto, N.; Ikeda, C.; Yamamura, M.; Nabeshima, T., Structural Interconversion and Regulation of Optical Properties of Stable Hypercoordinate Dipyrrin-Silicon Complexes. J. Am. Chem. Soc. 2011, 133, 4726-4729.

4. Song, H.; Rajendiran, S.; Koo, E.; Min, B. K.; Jeong, S. K.; Daniel Thangadurai, T.; Yoon, S., Fluorescence Enhancement of $\mathrm{N}_{2} \mathrm{O}_{2}$-type Dipyrrin Ligand in Two Step Responding to Zinc(II) Ion. J. Lumin. 2012, 132, 3089-3092.

5. Sumiyoshi, A.; Chiba, Y.; Matsuoka, R.; Noda, T.; Nabeshima, T., Efficient Luminescent Properties and Cation Recognition Ability of Heavy Group 13 Element Complexes of $\mathrm{N}_{2} \mathrm{O}_{2}$ - and $\mathrm{N}_{2} \mathrm{O}_{4}$-type Dipyrrins. Dalton Trans. 2019, 48, 13169-13175.

6. Yamamura, M.; Albrecht, M.; Albrecht, M.; Nishimura, Y.; Arai, T.; Nabeshima, T., Red/Near-Infrared Luminescence Tuning of Group-14 Element Complexes of Dipyrrins Based on a Central Atom. Inorg. Chem. 2014, 53, 1355-1360.

7. Yamamura, M.; Takizawa, H.; Nabeshima, T., Zwitterionic $\mathrm{N}_{2} \mathrm{O}_{2}$-Type Protonated Dipyrrin Bearing a Phosphate Anionic Moiety as a pH-Responsive Fluorescence Indicator. Org. Lett. 2015, 17, 3114-3117.

8. Yamamura, M.; Takizawa, H.; Sakamoto, N.; Nabeshima, T., Monomeric and Dimeric Red/NIR-fluorescent Dipyrrin-germanium Complexes: Facile Monomer-Dimer interconversion Driven by Acid/Base Additions. Tetrahedron Lett. 2013, 54, 7049-7052.

9. Yamamura, M.; Yazaki, S.; Seki, M.; Matsui, Y.; Ikeda, H.; Nabeshima, T., A Facile and High-yield Formation of Dipyrrin-Boronic Acid Dyads and Triads: A Light-Harvesting System in the Visible Region Based on the Efficient Energy Transfer. Org. Biomol. Chem. 2015, 13, 2574-2581.

10. El Ghachtouli, S.; Wojcik, K.; Copey, L.; Szydlo, F.; Framery, E.; Goux-Henry, C.; Billon, L.; Charlot, M.-F.; Guillot, R.; Andrioletti, B.; Aukauloo, A., Dipyrrinphenol-Mn(III) 
Complex: Synthesis, Electrochemistry, Spectroscopic Characterization and Reactivity. Dalton Trans. 2011, 40, 9090-9093.

11. Feng, Y.; Burns, L. A.; Lee, L.-C.; Sherrill, C. D.; Jones, C. W., Co(III) Complexes of Tetradentate $\mathrm{X}_{3} \mathrm{~L}$ Type Ligands: Synthesis, Electronic Structure, and Reactivity. Inorg. Chim. Acta 2015, 430, 30-35.

12. Lecarme, L.; Chiang, L.; Moutet, J.; Leconte, N.; Philouze, C.; Jarjayes, O.; Storr, T.; Thomas, F., The Structure of a One-Electron Oxidized Mn(III)-bis(phenolate)dipyrrin Radical Complex and Oxidation Catalysis Control via Ligand-Centered Redox Activity. Dalton Trans. 2016, 45, 16325-16334.

13. Lecarme, L.; Kochem, A.; Chiang, L.; Moutet, J.; Berthiol, F.; Philouze, C.; Leconte, N.; Storr, T.; Thomas, F., Electronic Structure and Reactivity of One-Electron-Oxidized Copper(II) Bis(phenolate)-Dipyrrin Complexes. Inorg. Chem. 2018, 57, 9708-9719.

14. Baudron, S. A., Dipyrrin Based Metal Complexes: Reactivity and Catalysis. Dalton Trans. 2020, 49, 6161-6175.

15. Copey, L.; Jean-Gérard, L.; Framery, E.; Pilet, G.; Andrioletti, B., Synthesis, Solid-State Analyses, and Anion-Binding Properties of meso-Aryldipyrrin-5,5'-diylbis(phenol) and bis(aniline) Ligands. Eur. J. Org. Chem. 2014, 2014, 4759-4766.

16. Kadish, K. M.; Van Caemelbecke, E.; Royal, G., Electrochemistry of Metalloporphyrins in Nonaqueous Media. In The Porphyrin Handbook, Kadish, K. M.; Smith, K. M.; Guilard, R., Eds. Academic Press: Burlington, MA, 2000; Vol. 8, pp 1-97.

17. Kadish, K. M., The Electrochemistry of Metalloporphyrins in Nonaqueous Media. In Prog. Inorg. Chem., Lippard, S. J., Ed. Wiley: New York, 1986; Vol. 34, pp 435-605.

18. Fang, Y.; Ou, Z.; Kadish, K. M., Electrochemistry of Corroles in Nonaqueous Media. Chem. Rev. 2017, 117, 3377-3419.

19. Erben, C.; Will, S.; Kadish, K. M., Metallocorroles: Molecular Structure, Spectroscopy and Electronic States In The Porphyrin Handbook, Kadish, K. M.; Smith, K. M.; Guilard, R., Eds. Academic Press: Burlington, MA, 2000; Vol. 2, pp 233-300.

20. Shan, W.; Desbois, N.; Pacquelet, S.; Stéphane, B.; Rousselin, Y.; Conradie, J.; Ghosh, A.; Gros, C. P.; Kadish, K. M., Ligand Noninnocence in Cobalt Dipyrrin-Bisphenols: Spectroscopic, Electrochemical, and Theoretical Insights Indicating an Emerging Analogy with Corroles. Inorg. Chem. 2019, 58, 7677-7689. 
21. Ghosh, A., Electronic Structure of Corrole Derivatives: Insights from Molecular Structures, Spectroscopy, Electrochemistry, and Quantum Chemical Calculations. Chem. Rev. 2017, 117, 3798-3881.

22. Thomas, K. E.; Desbois, N.; Conradie, J.; Teat, S. J.; Gros, C. P.; Ghosh, A., Gold Dipyrrinbisphenolates: A Combined Experimental and DFT Study of Metal-ligand Interactions. RSC Adv. 2020, 10, 533-540.

23. Kochem, A.; Chiang, L.; Baptiste, B.; Philouze, C.; Leconte, N.; Jarjayes, O.; Storr, T.; Thomas, F., Ligand-Centered Redox Activity in Cobalt(II) and Nickel(II) Bis(phenolate)Dipyrrin Complexes. Chem. Eur. J. 2012, 18, 14590-14593, S14590/1-S14590/51.

24. Yamamura, M.; Takizawa, H.; Gobo, Y.; Nabeshima, T., Stable Neutral Radicals of Planar $\mathrm{N}_{2} \mathrm{O}_{2}$-type Dipyrrin Platinum Complexes: Hybrid Radicals of the Delocalized Organic $\pi$ orbital and Platinum d-orbital. Dalton Trans. 2016, 45, 6834-6838.

25. Ganguly, S.; McCormick, L. J.; Conradie, J.; Gagnon, K. J.; Sarangi, R.; Ghosh, A., Electronic Structure of Manganese Corroles Revisited: X-ray Structures, Optical and Xray Absorption Spectroscopies, and Electrochemistry as Probes of Ligand Noninnocence. Inorg. Chem. 2018, 57, 9656-9669.

26. Krzystek, J.; Schnegg, A.; Aliabadi, A.; Holldack, K.; Stoian, S. A.; Ozarowski, A.; Hicks, S. D.; Abu-Omar, M. M.; Thomas, K. E.; Ghosh, A.; Caulfield, K. P.; Tonzetich, Z. J.; Telser, J., Advanced Paramagnetic Resonance Studies on Manganese and Iron Corroles with a Formal d ${ }^{4}$ Electron Count. Inorg. Chem. 2020, 59, 1075-1090.

27. Paszkiewicz, M.; Biktagirov, T.; Aldahhak, H.; Allegretti, F.; Rauls, E.; Schoefberger, W.; Schmidt, W. G.; Barth, J. V.; Gerstmann, U.; Klappenberger, F., Unraveling the Oxidation and Spin State of Mn-Corrole through X-ray Spectroscopy and Quantum Chemical Analysis. J. Phys. Chem. Lett. 2018, 9, 6412-6420.

28. Rausaria, S.; Kamadulski, A.; Rath, N. P.; Bryant, L.; Chen, Z.; Salvemini, D.; Neumann, W. L., Manganese(III) Complexes of Bis(hydroxyphenyl)dipyrromethenes Are Potent Orally Active Peroxynitrite Scavengers. J. Am. Chem. Soc. 2011, 133, 4200-4203.

29. Kadish, K. M.; Kelly, S., Electron-Transfer and Ligand-Addition Reactions of (mesoTetraphenylporphinato)Manganese(II) and -Manganese(III) Chloride. Inorg. Chem. 1979, 18, 2968-2971. 
30. Kelly, S. L.; Kadish, K. M., Counterion and Solvent Effects on the Electrode Reactions of Manganese Porphyrins. Inorg. Chem. 1982, 21, 3631-3639.

31. Shen, J.; El Ojaimi, M.; Chkounda, M.; Gros, C. P.; Barbe, J.-M.; Shao, J.; Guilard, R.; Kadish, K. M., Solvent, Anion, and Structural Effects on the Redox Potentials and UVvisible Spectral Properties of Mononuclear Manganese Corroles. Inorg. Chem. 2008, 47, 7717-7727.

32. Lansky, D. E.; Mandimutsira, B.; Ramdhanie, B.; Clausén, M.; Penner-Hahn, J.; Zvyagin, S. A.; Telser, J.; Krzystek, J.; Zhan, R.; Ou, Z.; Kadish, K. M.; Zakharov, L.; Rheingold, A. L.; Goldberg, D. P., Synthesis, Characterization, and Physicochemical Properties of Manganese(III) and Manganese(V)-Oxo Corrolazines. Inorg. Chem. 2005, 44, 4485-4498.

33. Zuman, P., Substituent Effects in Organic Polarography. Plenum Press: New York, 1967.

34. Shimizu, D.; Osuka, A., Porphyrinoids as a Platform of Stable Radicals. Chem. Sci. 2018, 9 , 1408-1423.

35. Gao, B.; Ou, Z.; Chen, X.; Huang, S.; Li, B.; Fang, Y.; Kadish, K. M., Spectroelectrochemical Characterization of meso Triaryl-substituted Mn(IV), Mn(III) and $\mathrm{Mn}(\mathrm{II})$ Corroles. Effect of Solvent and Oxidation State on UV-visible Spectra and Redox Potentials in Nonaqueous Media. J. Porphyrins Phthalocyanines 2014, 18, 1131-1144.

36. Ou, Z.; Erben, C.; Autret, M.; Will, S.; Rosen, D.; Lex, J.; Vogel, E.; Kadish, K. M., Manganese(III) and manganese(IV) Corroles: Synthesis, Spectroscopic, Electrochemical and X-ray Structural Characterization. J. Porphyrins Phthalocyanines 2005, 9, 398-412.

37. Bard, A. J.; Faulkner, L. R., Electrochemical Methods: Fundamentals and Applications. Wiley: New York, 2001; pp 226-260.

38. Chen, P.; El Ojaimi, M.; Gros, C. P.; Richard, P.; Barbe, J.-M.; Guilard, R.; Shen, J.; Kadish, K. M., Electrochemistry and Spectroelectrochemistry of Bismanganese Porphyrin-Corrole Dyads. Inorg. Chem. 2011, 50, 3479-3489.

39. Jiang, X.; Gros, C. P.; Chang, Y.; Desbois, N.; Zeng, L.; Cui, Y.; Kadish, K. M., Tetracationic and Tetraanionic Manganese Porphyrins: Electrochemical and Spectroelectrochemical Characterization. Inorg. Chem. 2017, 56, 8045-8057.

40. Fang, Y.; Wang, L.; Xu, W.; Ou, Z.; Chen, M.; Cong, L.; Shan, W.; Ke, X.; Kadish, K. M., Spectral, Electrochemical, and ESR Characterization of Manganese 
Tetraarylporphyrins Containing Four $\beta, \beta^{\prime}$-Pyrrole Fused Butano and Benzo Groups in Nonaqueous Media. Inorg. Chem. 2019, 58, 2576-2587.

41. Banu, K. S.; Chattopadhyay, T.; Banerjee, A.; Mukherjee, M.; Bhattacharya, S.; Patra, G. K.; Zangrando, E.; Das, D., Mono- and Dinuclear Manganese(III) Complexes Showing Efficient Catechol Oxidase Activity: Syntheses, Characterization and Spectroscopic Studies. Dalton Trans. 2009, 8755-8764.

42. Mitra, K.; Biswas, S.; Lucas, C. R.; Adhikary, B., Manganese(III) Complexes of $\mathrm{N}_{2} \mathrm{O}_{2}$ Donor 5-bromosalicylideneimine Ligands: Combined Effects of Electron WIthdrawing Substituents and Chelate Ring Size Variations on Electrochemical Properties. Inorg. Chim. Acta 2006, 359, 1997-2003.

43. Palopoli, C.; Gómez, G.; Foi, A.; Doctorovich, F.; Mallet-Ladeira, S.; Hureau, C.; Signorella, S., Dimerization, Redox Properties and Antioxidant Activity of Two Manganese(III) Complexes of Difluoro- and Dichloro-Substituted Schiff-base Ligands. J. Inorg. Biochem. 2017, 167, 49-59.

44. Kamlet, M. J.; Abboud, J. L. M.; Abraham, M. H.; Taft, R. W., Linear Solvation Energy Relationships. 23. A Comprehensive Collection of the Solvatochromic Parameters, $\pi^{*}, \alpha$, and $\beta$, and Some Methods for Simplifying the Generalized Solvatochromic Equation. $J$. Org. Chem. 1983, 48, 2877-2887.

45. E. Hulme, C.; Watkinson, M.; Haynes, M.; G. Pritchard, R.; A. McAuliffe, C.; Jaiboon, N.; Beagley, B.; Sousa, A.; R. Bermejo, M.; Fondo, M., Structurally Diverse Manganese(III) Complexes of Yetradentate $\mathrm{N}_{2} \mathrm{O}_{2}$ Schiff-base Ligands with Ancillary Carboxylate Donors. J. Chem. Soc., Dalton Trans. 1997, 1805-1814.

46. Reichardt, C., Empirical Parameters of the Polarity of Solvents. Angew. Chem. Int. Ed. 1965, 4, 29-40.

47. Reichardt, C., Solvatochromic Dyes as Solvent Polarity Indicators. Chem. Rev. 1994, 94, 23192358.

48. Xuan, S.; Zhao, N.; Ke, X.; Zhou, Z.; Fronczek, F. R.; Kadish, K. M.; Smith, K. M.; Vicente, M. G. H., Synthesis and Spectroscopic Investigation of a Series of Push-Pull Boron Dipyrromethenes (BODIPYs). J. Org. Chem. 2017, 82, 2545-2557.

49. Measured under the same solution conditions as ( $\mathrm{Ar}) \mathrm{DPPMn}$ in $\mathrm{CH}_{3} \mathrm{CN} 0.1 \mathrm{M} \mathrm{TBAPF}_{6}$. Nearly identical values can be seen in ref. 30 . 
50. Liu, H.-Y.; Mahmood, M. H. R.; Qiu, S.-X.; Chang, C. K., Recent Developments in Manganese Corrole Chemistry. Coord. Chem. Rev. 2013, 257, 1306-1333.

51. Thomas, K. E.; Vazquez-Lima, H.; Fang, Y.; Song, Y.; Gagnon, K. J.; Beavers, C. M.; Kadish, K. M.; Ghosh, A., Ligand Noninnocence in Coinage Metal Corroles: A Silver Knife-Edge. Chem. Eur. J. 2015, 21, 16839-16847.

52. Jiang, X.; Shan, W.; Desbois, N.; Quesneau, V.; Brandès, S.; Caemelbecke, E. V.; Osterloh, W. R.; Blondeau-Patissier, V.; Gros, C. P.; Kadish, K. M., Mono-DMSO Ligated Cobalt Nitrophenylcorroles: Electrochemical and Spectral Characterization. New J. Chem. 2018, $42,8220-8229$.

53. Frisch, M. J.; Trucks, G. W.; Schlegel, H. B.; Scuseria, G. E.; Robb, M. A.; Cheeseman, J. R.; Scalmani, G.; Barone, V.; Petersson, G. A.; Nakatsuji, H.; Li, X.; Caricato, M.; Marenich, A. V.; Bloino, J.; Janesko, B. G.; Gomperts, R.; Mennucci, B.; Hratchian, H. P.; Ortiz, J. V.; Izmaylov, A. F.; Sonnenberg, J. L.; Williams; Ding, F.; Lipparini, F.; Egidi, F.; Goings, J.; Peng, B.; Petrone, A.; Henderson, T.; Ranasinghe, D.; Zakrzewski, V. G.; Gao, J.; Rega, N.; Zheng, G.; Liang, W.; Hada, M.; Ehara, M.; Toyota, K.; Fukuda, R.; Hasegawa, J.; Ishida, M.; Nakajima, T.; Honda, Y.; Kitao, O.; Nakai, H.; Vreven, T.; Throssell, K.; Montgomery Jr., J. A.; Peralta, J. E.; Ogliaro, F.; Bearpark, M. J.; Heyd, J. J.; Brothers, E. N.; Kudin, K. N.; Staroverov, V. N.; Keith, T. A.; Kobayashi, R.; Normand, J.; Raghavachari, K.; Rendell, A. P.; Burant, J. C.; Iyengar, S. S.; Tomasi, J.; Cossi, M.; Millam, J. M.; Klene, M.; Adamo, C.; Cammi, R.; Ochterski, J. W.; Martin, R. L.; Morokuma, K.; Farkas, O.; Foresman, J. B.; Fox, D. J. Gaussian 16, Revision B.01; Guassian, Inc: Wallingford, CT, 2016.

54. Becke, A. D., Density - Functional Thermochemistry. III. The Role of Exact Exchange. J. Chem. Phys. 1993, 98, 5648-5652.

55. Lee, C.; Yang, W.; Parr, R. G., Development of the Colle-Salvetti Correlation-Energy Formula into a Functional of the Electron Density. Physical Review B 1988, 37, 785-789.

56. Stephens, P. J.; Devlin, F. J.; Chabalowski, C. F.; Frisch, M. J., Ab Initio Calculation of Vibrational Absorption and Circular Dichroism Spectra Using Density Functional Force Fields. J. Phys. Chem. 1994, 98, 11623-11627. 
57. Weigend, F.; Ahlrichs, R., Balanced Basis Sets of Split Valence, Triple Zeta Valence and Quadruple Zeta Valence Quality for H to Rn: Design and Assessment of Accuracy. Phys. Chem. Chem. Phys. 2005, 7, 3297-3305.

58. Marenich, A. V.; Cramer, C. J.; Truhlar, D. G., Universal Solvation Model Based on Solute Electron Density and on a Continuum Model of the Solvent Defined by the Bulk Dielectric Constant and Atomic Surface Tensions. J. Phys. Chem. B 2009, 113, 6378-6396.

59. Zhurko, G. A., Zhurko, D. A. ChemCraft, Version 1.8; 2017; http://www.chemcraftprog.com. 
TOC Graphic. A series of " $\mathrm{N}_{2} \mathrm{O}_{2}$-type" manganese dipyrrin-bisphenols (DPP), formulated as (Ar)DPPMn, where $\mathrm{Ar}=$ pentafluorophenyl $\left(\mathrm{F}_{5} \mathrm{Ph}\right)$, phenyl $(\mathrm{Ph})$ or mesityl $(\mathrm{Mes})$, were electrochemically and spectroscopically characterized in nonaqueous media with and without added anions in the form of tetrabutylammonium salts ( $\mathrm{TBAX}$ where $\mathrm{X}=\mathrm{ClO}_{4}^{-}, \mathrm{PF}_{6}^{-}, \mathrm{BF}_{4}^{-}, \mathrm{F}^{-}, \mathrm{Cl}^{-}, \mathrm{OH}^{-}$or $\left.\mathrm{CN}^{-}\right)$.

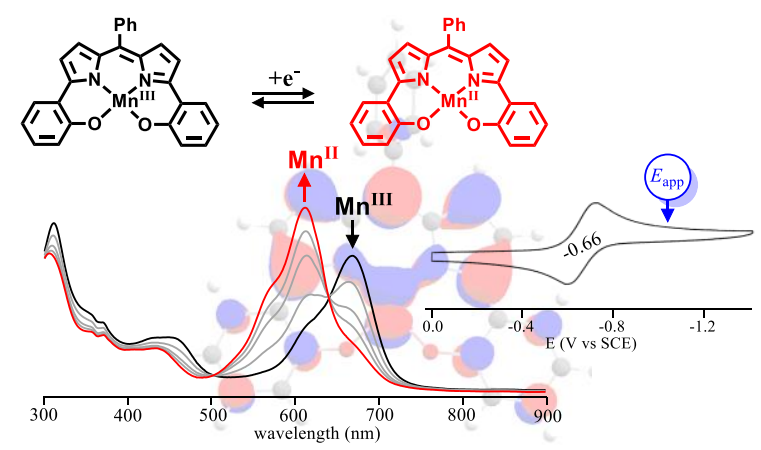

